NBER WORKING PAPER SERIES

\title{
FINANCIAL GLOBALIZATION AND EMERGING MARKETS: WITH OR WITHOUT CRASH?
}

\author{
Philippe Martin \\ Hélène Rey
}

Working Paper 9288

http://www.nber.org/papers/w9288

\author{
NATIONAL BUREAU OF ECONOMIC RESEARCH \\ 1050 Massachusetts Avenue \\ Cambridge, MA 02138 \\ October 2002
}

We thank Daniel Cohen, Gene Grossman, Enrique Mendoza, Lars Svensson and Aaron Tornell as well as participants at many seminars for helpful comments. We also thank Graciela Kaminsky and Sergio Schmukler for the stock market data. Rachel Polimeni provided excellent research assistance. The paper was written while Philippe Martin was visiting the Federal Reserve Bank of New York, which provided a most stimulating environment. The views expressed here are those of the authors and do not necessarily reflect the position of the Federal Reserve Bank of New York or the Federal Reserve System. This paper is part of a research network on .The Analysis of International Capital Markets: Understanding Europe's Role in the Global Economy., funded by the European Commission under the Research Training Network Program (Contract No. HPRN.CT.1999.00067). The views expressed herein are those of the authors and not necessarily those of the National Bureau of Economic Research.

(C) 2002 by Philippe Martin and Hélène Rey. All rights reserved. Short sections of text, not to exceed two paragraphs, may be quoted without explicit permission provided that full credit, including (C notice, is given to the source. 
Financial Globalization and Emerging Markets: With or Without Crash?

Philippe Martin and Hélène Rey

NBER Working Paper No. 9288

October 2002

JEL No. F3, F4, E0, G1

$\underline{\text { ABSTRACT }}$

We analyze the impact of financial globalization on asset prices, investment and the possibility of crashes driven by self-fulfilling expectations in emerging markets. In a two-country model with one emerging market (intermediate income level) and one industrialized country (high income level), we show that liberalization of capital flows increases asset prices, investment and income in the emerging market. However, for intermediate levels of international financial transaction costs, we find that pessimistic expectations can be self-fulfilling, leading to a financial crash. The crash is accompanied by capital flight, a drop in income and investment below the financial autarky level and more market incompleteness. We show that emerging markets are more prone to financial crashes simply because they have a lower income level and not because of the existence of market failures (moral hazard or credit constraints), bad monetary policies or exchange rate regimes.

Philippe Martin

Université Paris 1

Panthéon Sorbonne

CERAS-ENPC

48 Boulevard Jourdan

75014 Paris, France

martin-p@enpc.fr
Hélène Rey

Department of Economics and Woodrow Wilson School

Princeton University

Princeton, NJ 08544

and NBER

hrey@princeton.edu 


\section{Introduction}

When capital flows more easily into and out of emerging markets, do these markets reap the benefits of increased investment and a better ability to diversity their risk? Or do they face an increased likelihood of financial crash? The empirical literature seems to point towards the relevance of both these outcomes. On the one hand, a number of papers in the finance literature ${ }^{1}$ show that financial opening in emerging markets leads to a decrease in the cost of equity capital and can have a positive effect on domestic investment. The macroeconomic literature ${ }^{2}$, using cross-country data, finds more tenuous evidence that financial opening contributes positively to long-run growth. On the other hand, a voluminous literature on financial crisis emphasizes the risks of liberalization and the fragility of emerging markets financial systems to capital mobility. Wyplosz (2001) finds that external financial liberalization is considerably more destabilizing in developing countries than in developed countries: it generates a boom-bust cycle. Another strand of literature, surveyed by Aizenman (2002) ${ }^{3}$ concludes that liberalization of capital flows has contributed to both banking and currency crises in emerging markets. Kaminski and Schmukler (2001) show that stock markets become more volatile in the three years following financial liberalization. They tend however to be more stable in the long run.

Figures 1 and 2 also suggest that financial openness alters the relation between the frequency of financial crashes and the level of income per capita. A crash is defined as a monthly drop in the stock index (in dollars) larger than two standard deviations of the average monthly change. We plot on the vertical axis the number of stock market crashes per year. Countries are ranked by log of GDP per capita on the horizontal axis. We divided the sample in periods for which countries were financially open and financially closed. Hence, among our 62 countries (34 emerging countries) 31 appear twice as they changed status during the sample years. Appendix 1 provides more details on the data and the way we define financial openness.

Figure 1 makes clear that for countries which have not opened to capital movements, no relation exists between the frequency of crashes and the log of GDP per capita, whether Argentina, an obvious outlier, is included or not. Statistically, a weakly negative but not significant relation exists. On the other hand, figure 2 illustrates that for countries which have opened to capital movements a negative relation between the frequency of crashes and income per capita exists. This relation is statistically significant. We have checked that this negative relative relation (and the absence of such relation for closed economies) is robust to changes of the definition of financial openess.

\footnotetext{
${ }^{1}$ See Bekaert and Harvey (2001), Bekaert, Harvey and Lundblad, (2001), Henry (2000), Chari and Henry (2002) and de Jong and de Roon (2001).

${ }^{2}$ Edwards (2001) finds that opening the capital account positively affects growth only after the country has achieved a certain degree of economic development. McKenzie (2001) concludes that restrictions on current account payments, but not capital transactions, affect growth negatively. Arteta, Eichengreen and Wyplosz (2001) show that capital account liberalization has a significant positive growth effect contingent on the absence of macroeconomic imbalances.

${ }^{3}$ See for example, Eichengreen, Rose and Wyplosz (1995), Rossi (1999), Demigüc-Kunt and Detragiache (1998), Kaminsky and Reinhart (1999).
} 


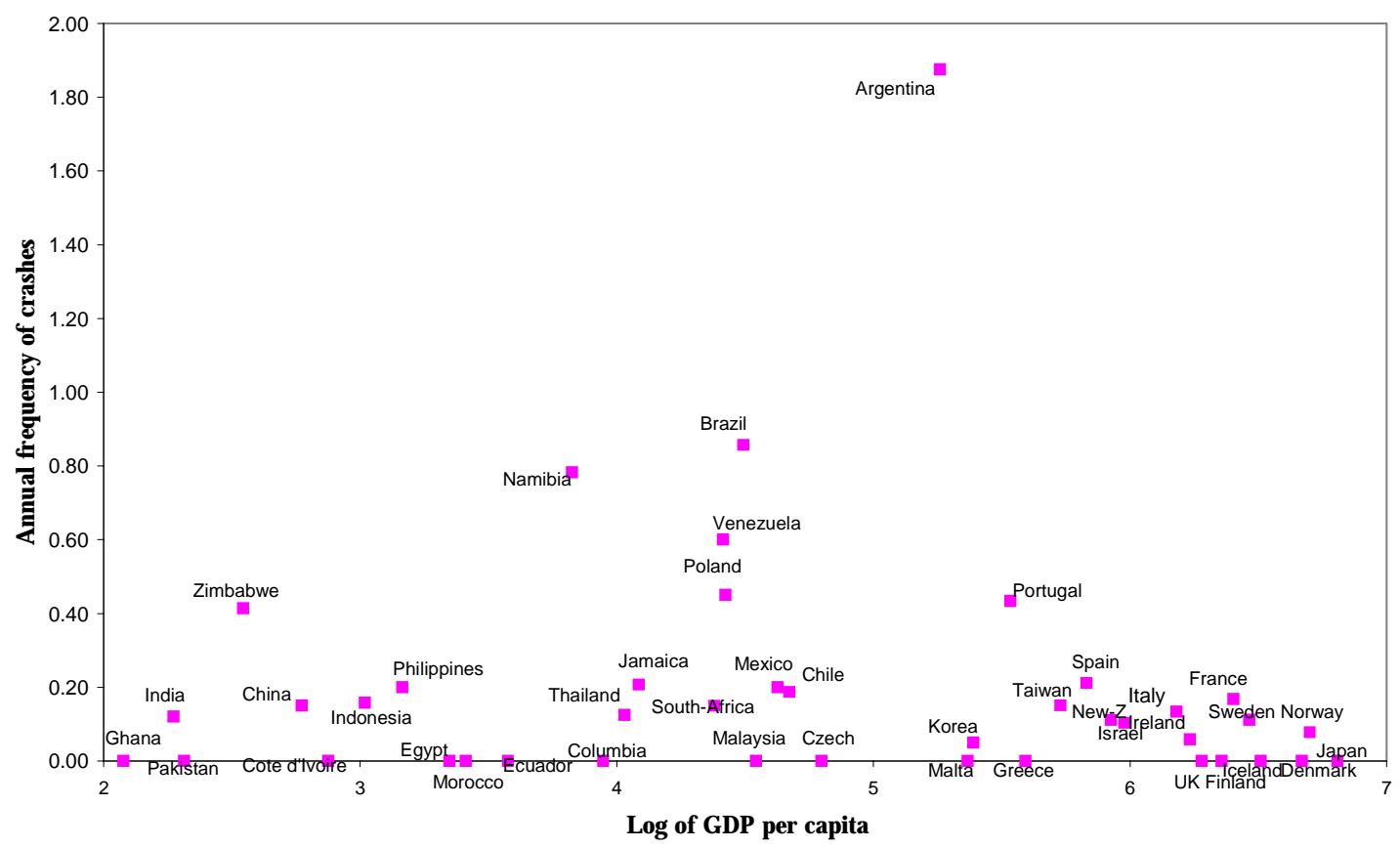

Figure 1: Financially closed economies

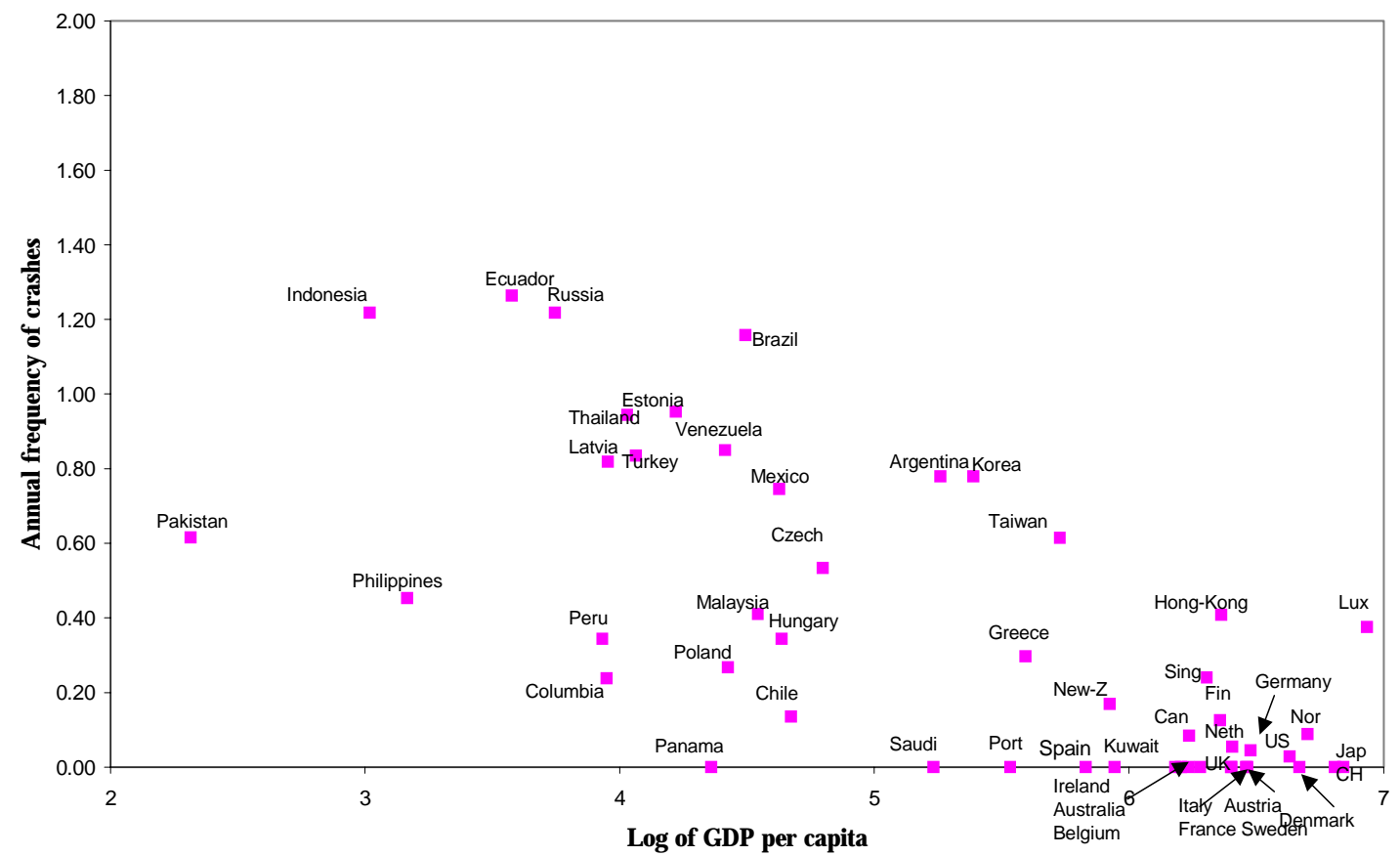

Figure 2: Financially open economies 
Except for the clear exception of Argentina (which has by far the highest number of crashes) and to a lesser extent Chile, all emerging markets experience an increase in the frequency of crashes once they liberalize. The table below gives the average annual frequency of crashes for developed (defined as countries with GDP per capita above South-Korea) and emerging countries.

\begin{tabular}{|l|l|l|}
\hline Frequency of crashes & developed & emerging \\
\hline closed countries & $8.8 \%$ & $25.1 \%$ \\
\hline open countries & $9.7 \%$ & $61.6 \%$ \\
\hline
\end{tabular}

The table strongly suggests that opening to capital movements has a much more dramatic effect on the frequency of crashes in emerging markets than in developed ones, a point consistent with the literature cited above on the effect of capital opening on crises in emerging markets.

This paper presents a general framework in which the two effects of financial globalization on emerging markets- the decreased cost of capital and the increased frequency of crashes - can be reconciled. We also make sense of the differential impact of financial globalization in emerging markets and developed countries. In our model, reducing asset market segmentation between emerging markets and developed countries increases asset prices, investment and income in the emerging market. Thus financial liberalization does perform its positive role of expanding diversification opportunities and lowering the cost of investment in emerging markets. In certain circumstances, however, financial liberalization can facilitate financial crashes. We show that emerging markets, if sufficiently open to capital movements, are more prone to financial crashes. This is due to the mere fact that their income is lower than developed countries and not necessarily because of fundamental macro-economic imbalances, a bad choice of exchange rate regime or the existence of market failures such as "moral hazard", credit constraints or an 'over-borrowing syndrome'. The point we are making here is therefore very general. In our model, the decision to invest by one agent influences the cost of capital of other investors through the impact of that decision on income and the price of assets. The type of market failure we build upon can therefore best be described as a pecuniary externality.

We present a two-country model of the world economy (one generic emerging market and one generic developed market). The emerging market and the developed economy differ only in the productivity levels of their labor. In both countries, domestic entrepreneurs decide whether or not to invest in risky fixed-sized projects, sell shares of their projects on the stock exchange, and acquire shares in other risky ventures developed at home or abroad.

When entrepreneurs expect that aggregate investment in their economy is large, they expect aggregate income and demand for equity investment to be high as well. Because assets are imperfect substitutes and transaction costs on international trade in assets give rise to a home bias in asset holding, this in turn means that the expected price of their shares on the stock exchange will be high. The high prospective prices give them an incentive to invest in a large number of risky projects. In 
such a case, facilitating capital flows increases investment in the emerging market, because it reduces its disadvantage of having a low income level that translates into low demand for domestic assets and high cost of capital. This is the demand effect that is identified in Martin and Rey (2001). This paper discusses in detail the empirical evidence that supports the existence of such demand effects on asset prices. In particular, Schleifer (1986) disentangles information effects from pure demand effects and shows that an exogenous demand shift leads to significantly higher asset prices.

The same logic may however go in the other direction: if entrepreneurs expect low levels of aggregate investment, they also contemplate a low level of aggregate income and do not expect to be able to raise capital at a good price. This deters them from developing risky projects. In such a case, domestic investors turn to the developed country stock exchange to buy equity shares and there are capital outflows from the emerging market to developed countries. This circular chain of causality creates the possibility of multiple equilibria as long as investing in risky projects requires a fixed cost. The "good equilibrium" is characterized by high asset prices, income and investment and in this case financial integration is beneficial to the emerging market on these three dimensions. We call a crash the "bad equilibrium", characterized by a coordination failure resulting in low asset prices, income and investment. The likelihood that it exists is higher at an intermediate degree of financial segmentation. The reason why instability and crashes occur only for intermediate degrees of capital account liberalizations in our model can be understood as follows. If financial markets are perfectly integrated, international arbitrage ensures that asset prices are the same in the developed country and the emerging market. This rules out the possibility of multiple equilibria, since the price of equity shares in the emerging market is pinned down by the price of capital worldwide and independent of domestic expectations. Symmetrically, if financial asset markets are very segmented internationally, emerging markets agents have no choice but to invest at home since capital outflows are heavily restricted. This rules out capital flight and multiple equilibria but leads to a suboptimal world allocation of resources with lower equity prices (and therefore a higher cost of capital) in the emerging market compared to the developed country. In the model, lower income countries are more prone to financial crashes. The reason is that pessimistic expectations always have more dramatic consequences on the expected asset prices in the lower income market.

In our model, asset prices and equity markets play a key role. The importance of stock markets in emerging economies has increased substantially in the past decade, as documented by Claessens, Klingebiel and Schmukler (2001). However, we believe the mechanism identified in this paper is not specific to the channel through which firms finance investment. Suppose firms were to finance investment projects through bank loans. As long as banks do not consider these projects and the associated bank loans to be perfect substitutes and that there exist transaction costs when banks lend to foreign firms, the real interest rate charged by banks could be different across countries even for projects with identical risk. If higher domestic expected investment and therefore income leads 
to a larger pool of saving, which because of imperfectly integrated financial markets, benefits more (through a lower interest rate) the domestic firms, then the key ingredients behind the circular causality mechanism that we analyze in this paper would also be present.

A closely related paper is Matsuyama (2001), who studies the impact of financial globalization on inequality across countries when there is a borrowing constraint in domestic capital markets. Like Matsuyama (2001), we find that in some cases, financial globalization leads to increased inequality across nations. One advantage of our model is that we are able to analyze all the intermediate cases of financial globalization (he contrasts autarky with free capital mobility). Also, we do not rely on any specific assumption regarding credit constraints on the domestic capital market. Instead we make the simple and realistic assumption that labor is more productive in one country than in the other. Acemoglu and Zilibotti (1997) analyze development patterns in an economy with risky indivisible projects and show that free capital mobility may first lead to divergence with capital flowing to the richer country and then a reversal of capital flows with convergence at a faster rate than if the two economies were closed. In their paper, as in Pagano (1993), multiple equilibria may exist because assets are complements: the higher the number of assets, the more valuable existing assets become. This is not the mechanism at work in our model as assets are substitutes and multiple equilibria arise through an income effect.

Our paper is also related to the new trade and new economic geography literature, in particular Krugman and Venables (1995) because our modelling of asset trade and of transaction costs has some similarities with the modelling of trade in goods in this literature. They show that "catastrophic" agglomeration of industries takes place for intermediate levels of trade costs because of cost and demand linkages. The mechanisms and results we describe are however different in particular because of the intertemporal nature of our model. In new trade and new economic geography models, lower transaction costs strengthen the "home market effect" in the sense that the richer country specializes more in the goods produced with increasing returns. In our model, lowering transaction costs on asset trade has the opposite result in the equilibrium without a crash: it weakens the "home market effect" in the sense that it increases the asset price of the poorer country and leads to more investment in that country. The reason is that lower transaction costs not only induce more portfolio diversification but also more intertemporal trade which implies that the richer country demands more assets from the poorer country.

More generally, our work is related both to the literature on financial integration (see Stulz 2001 for a survey) and to the literature on self-fulfilling financial crises in emerging markets. Aghion, Bachetta and Banerjee (2000) find that countries with intermediate levels of domestic financial development and free capital movements are more prone to macroeconomic volatility. In contrast to their paper and most of the existing literature, however, the vulnerability of emerging markets to financial crises in our model does not result from strong assumptions distinguishing emerging markets from developed 
countries. In particular, we do not assume the existence of credit constraints on capital markets and their implied balance sheets effects (as in Diaz-Alejandro, 1985, Chang and Velasco, 1998, Meng and Velasco, 1999, Krugman, 1999, Aghion, Bachetta, and Banerjee, 2000, Caballero and Krishnarmurthy, 1998 and 2000, Schneider and Tornell, 2000, Mendoza, 2001, Mendoza and Smith, 2001) or of moral hazard (as in Burnside, Eichenbaum and Rebello, 1998, McKinnon and Pill, 1999 and Corsetti, Pesenti and Roubini, 1999). Note finally that in our model a financial crash can occur irrespective of the exchange rate regime and without any currency mismatch.

Section 2 of the paper presents the model. Section 3 describes the properties of the equilibrium when things go well. Section 4 investigates the conditions necessary for a financial crash to occur. Section 5 and 6 analyze the impact of asymmetric external financial liberalization and domestic financial liberalization respectively. Some welfare issues are considered in Section 7 and Section 8 concludes.

\section{The model}

There are two countries $E$ (emerging) and $I$ (industrialized) and two periods. In the beginning of the first period, $L$ identical agents endowed with one unit of labor work. They also decide whether and how much to invest in risky projects which yield dividends in the second period. The good produced in the first period has labor as its only input and is freely tradable on a competitive market. It serves as the numeraire. The industrialized country has a higher marginal productivity of labor than the emerging country, so that its wage rate $w_{I}$, equal to marginal productivity, is higher than $w_{E}$ in the emerging country. This is the only asymmetry between the two countries that we assume.

The cost for an individual of engaging in investment projects is $F+f\left(z_{E}\right)$, where $z_{E}$ is the number of projects undertaken by a typical agent in the emerging market. We assume that these projects are of fixed unit size. The cost function for projects is convex and has a quadratic functional form ${ }^{4}$ : $f\left(z_{E}\right)=\frac{1}{2} z_{E}^{2}$. A similar form applies to the industrialized country. In both locations, the marginal cost of undertaking projects rises as an agent decides to invest in more projects. As these projects are different from each other (see below for their payoff structure), the idea is that as investors do more projects they lose the advantage of specialization. In addition, a fixed cost $F$ has to be paid to start investing in projects. We assume that this fixed cost is paid individually by each investor to all other agents in the economy so that aggregate income is not affected by the fixed $\operatorname{cost}^{5}$. This can be interpreted for example as a fixed cost to become an entrepreneur such as a flat fee paid to the government and redistributed at the end of the period.

The first period is without uncertainty. In the second period, there are $N$ exogenous and equally likely states of nature, and the realization is revealed at the beginning of that period. As in Acemoglu and Zilliboti (1998) and Martin and Rey (2001), the risky investment projects are such that each

\footnotetext{
${ }^{4}$ We discuss in appendix VI how our results would be affected by a more general convex cost function.

${ }^{5}$ If the fixed cost has an impact on aggregate income, the main results of the model are unaffected. However, the results are analytically less tractable.
} 
project gives dividends in only one state of nature. The payoff structure is such that project $i$ yields $d$ in state $i$ and 0 otherwise. Note that investment projects in the two countries have the exact same ex-ante expected dividend, $d / N$. All projects are traded on the stock market at the end of period one, so that each project corresponds to an asset. This implies that buying a share in a specific project is equivalent to investing in a Arrow-Debreu security that pays in only one state of nature. This will give agents in both countries a strong incentive for diversification that will materialize in the purchase of shares of both foreign and domestic projects. No duplication occurs in equilibrium so that each project/asset in the world is unique ${ }^{6}$. This could obviously lead to some exercise of monopolistic power. We however assume that project developers do not exploit this potential power. The issue of monopolistic competition in this type of framework is dealt with in Martin and Rey (2001) who show that it creates another source of financial home bias.

We assume that the number of states of nature $N$ is large enough so that $N>Z^{w}$ where $Z^{w}=$ $L\left(z_{E}+z_{I}\right)$ is the total number of investment projects/assets issued in the world. $N-Z^{w}$ is the endogenous degree of incompleteness of financial markets as the number of investment projects/assets is itself endogenous. Hence, the matrix of payoffs of projects has the following form:

$\begin{aligned} & \stackrel{Z^{w}}{\longleftrightarrow} \\ & {\left[\begin{array}{cccccc}d & 0 & 0 & \ldots & 0 & 0 \\ 0 & d & 0 & \ldots & 0 & 0 \\ 0 & 0 & d & \ldots & 0 & 0 \\ \ldots & \ldots & \ldots & \ldots & \ldots & \ldots \\ 0 & 0 & 0 & \ldots & 0 & 0 \\ 0 & 0 & 0 & \ldots & 0 & 0\end{array}\right] }\end{aligned}$

At the end of the first period, consumption takes place. Shares in the projects are sold on each of the stock markets. These shares can be traded internationally but international trade in assets between the industrialized country and the emerging market entails a transaction cost. An agent in either country who wants to buy assets in the other market must pay such a $\operatorname{cost}^{7}$, which may capture government regulations on capital flows, differences in regulations in accounting, banking and commission fees, exchange rate transaction fees and information costs. Gordon and Bovenberg (1996) use a similar type of proportional transaction costs on capital flows and focus on the cost of acquiring information about foreign countries. We will interpret financial globalization as a process through which these transaction costs are reduced but not eliminated. The situation of zero transaction costs will be interesting theoretically but we do not see it as empirically relevant. The presence of

\footnotetext{
${ }^{6}$ It can be checked that no investor has an incentive to duplicate an existing project as long as the total number of projects/assets is less than the number of states of nature. We assume that $\mathrm{N}$ is large enough so that this the case. The intuition is that as long as some states of nature have not been covered, the price of an asset associated to these states will always be higher than if the agent was to replicate an existing project/asset.

${ }^{7}$ These costs are borne by the buyer. The results would be identical if sellers were to pay them.
} 
these transaction costs will translate into a home bias in asset holdings. We denote the transaction costs on inflows $\tau_{\text {in }}$, and assume that they take the form of an iceberg $\operatorname{cost}^{8}$. This implies that the transaction fee is paid in shares and the resource cost is borne is second period. Agents have to buy $1+\tau_{\text {in }}>1$ units of shares to receive one share. This modelling implies that the transaction involved by international trade in assets consumes real resources. Similarly, an agent in the emerging market who buys shares from the industrialized country must pay a transaction cost $1+\tau_{\text {out }}>1$ on these outflows. We will analyze both the case of symmetric liberalization - where these transaction costs are lowered simultaneously - and the case of asymmetric liberalization. Transaction costs could also be levied on dividends that are repatriated. This would increase the home bias as shown in Martin and Rey (2001). Also, as in Obstfeld and Rogoff (2001), the financial home bias could be derived in our model from the existence of transport costs on goods as goods need eventually to be shipped in the second period to pay the dividends.

We assume that the utility of an agent in each country is given by the non-expected utility function introduced by Epstein and Zin (1989) and Weil $(1989,1990)$. This allows the intertemporal elasticity of substitution (which we assume to be 1 for simplicity) to be different from the coefficient of relative risk aversion $\rho$.

$$
U_{i}=\ln c_{i 1}+\beta \ln \left[\sum_{n=1}^{N} \frac{1}{N} c_{i 2}(n)^{1-\rho}\right]^{\frac{1}{1-\rho}} \quad i=E, I
$$

The first-period budget constraint of an agent in $E$ who undertakes projects is:

$$
Y_{E}=c_{E 1}+\sum_{i=1}^{L z_{E}} p_{E i} s_{E i}+\sum_{j=1}^{L z_{I}}\left(1+\tau_{o u t}\right) p_{I j} s_{E j}=w_{E}+\sum_{h=1}^{z_{E}} p_{E h}-F-f\left(z_{E}\right)+T
$$

where $Y_{E}$ is per-capita income in first period of the emerging country, $T$ is the transfer (which in equilibrium is equal to $F$ ) and $s_{E i}$ and $s_{E j}$ are demands for shares of risky projects developed in the emerging market and in the industrialized country respectively. $p_{E i}$ and $p_{I j}$ are the prices of the different assets. The budget constraint in the industrialized country is analogous. In the last period, income and consumption derive only from dividends of shares purchased in the first period. Hence, the budget constraint for an agent in $E$ is given by:

$$
c_{2 E}(n)=d s_{E n}, n \in\left[1, Z^{w}\right]
$$

where we already made use of the fact that only a subset $Z^{w}=L\left(z_{E}+z_{I}\right)$ of the $N$ states of nature are spanned by traded assets. Hence, we can rewrite the utility of an agent in the emerging market as:

\footnotetext{
${ }^{8}$ These iceberg transaction costs are borrowed from the trade and geography literature. See Martin and Rey (2001) for a more precise description. This modelization allows the elasticity of substitution between assets to be the same for all agents and also does not require the formal introduction of a sector that performs the transaction.
} 


$$
U_{i}=\ln c_{i 1}+\ln \beta \frac{d}{N^{1 /(1-\rho)}}+\beta \ln \left[\sum_{i=1}^{L z_{E}} s_{E i}^{1-\rho}+\sum_{j=1}^{L z_{I}} s_{I j}{ }^{1-\rho}\right]^{\frac{1}{1-\rho}}
$$

Note that in second period, this utility function is similar to the one introduced by Dixit and Stiglitz to represent preferences for differentiated products. Because in equilibrium markets are incomplete, consumption in second period is zero in some states of nature ${ }^{9}$. We therefore need to restrict $\rho$ to be between 0 and 1. As $\rho$ is the inverse of the elasticity of substitution between assets (see below), this again resembles the assumption in the differentiated products literature that the elasticity of substitution between different varieties is greater than 1 . This restriction also implies that assets are substitutes rather than complements as in Acemoglu and Zilibotti (1997) so that a source of multiple equilibria that they analyse does not exist here.

\section{W hen things go well}

\subsection{Investment and portfolio decisions}

Agents in both countries choose consumption $\left(c_{E 1}\right.$ and $\left.c_{I 1}\right)$ and investment (the number of projects $z_{E}$ and $z_{I}$ ) at the beginning of the first period. For this, they need to form expectations about the number of projects in which other agents will engage, because it will have an impact on the price of the assets that they will sell at the end of the first period. We will see in the next section that a coordination problem can arise such that in some equilibria, no investment is performed. We first solve the model for the case of an equilibrium in which both countries invest in risky projects $\left(z_{E}, z_{I}>0\right)$ so that no "crash" occurs. Agents choose optimally their portfolio of assets (domestic and foreign). For notational simplicity, we note that as projects/assets are ex-ante symmetric, the demand for each asset in a given country will be identical ${ }^{10}$ : we call $s_{E E}$ the demand for shares of a "typical" asset in the $E$ market by an agent in that market. $s_{E I}$ is the demand for an asset of the $I$ market by an agent in the $E$ market. Also, because of the symmetry of projects and agents in each country, all assets in a given country have the same price which we denote by $p_{E}$ and $p_{I}$, respectively.

Hence, the equilibrium is defined as a set of allocations $\left[c_{E 1}, c_{I 1}, z_{E}, z_{I}, c_{E 2}(n), c_{I 1}(n)\right]$, portfolio shares $\left[s_{E E}, s_{E I}, s_{I I}, s_{I E}\right]$ and asset prices $\left[p_{E}, p_{I}\right]$ such that: 1) $\left[c_{E 1}, z_{E}, s_{E E}, s_{E I}, c_{E 2}(n)\right] \operatorname{maxi}-$ mize $U_{E}$ subject to $E$ 's budget constraints (equations (2) and (3)); 2) $\left[c_{I 1}, z_{I}, s_{I I}, s_{I E}, c_{I 2}(n)\right] \max$ imize $U_{I}$ subject to $I$ 's budget constraints (the analogous of equations (2) and (3)); 3) asset markets clear: $L s_{E E}+L\left(1+\tau_{\text {in }}\right) s_{I E}=1$ and $\left.L s_{I I}+L\left(1+\tau_{\text {out }}\right) s_{E I}=1 ; 4\right)$ Goods markets clear: $L\left[c_{E 1}+c_{I 1}+f\left(z_{E}\right)+f\left(z_{I}\right)\right]=L\left(w_{E}+w_{I}\right)$.

\footnotetext{
${ }^{9}$ We discuss in section 4 how the inclusion of riskless projects that would allow consumption to be positive in all states of nature would affect our results.

${ }^{10}$ In a given country, agents are different in the sense that they choose different projects but they choose identical portfolios and consumption patterns.
} 
The first order conditions for maximization for an agent in the emerging market imply the following (where expectations are denoted by a superscript $e$ ):

$$
\begin{gathered}
z_{E}=p_{E}^{e} \\
c_{E 1}=\frac{Y_{E}}{1+\beta} \\
s_{E E}=\left(\frac{\beta Y_{E}}{1+\beta}\right)^{1 / \rho} p_{E}^{-1 / \rho}\left[\sum_{i=1}^{L z_{E}} s_{E}^{1-\rho}+\sum_{j=1}^{L z_{I}} s_{I j}^{1-\rho}\right]^{-1 / \rho}
\end{gathered}
$$

The equality between marginal cost and the expected price of the asset implies that the number of projects depends positively on the expected share price. Note also that the elasticity of substitution between assets is constant and equal to the inverse of the coefficient of relative risk aversion, $\rho$. Analogous conditions hold in the industrialized country.

For all agents in the economy to invest, it must be that the expected profitability of such projects is positive, or $p_{E}^{e} z_{E}-\frac{1}{2} z_{E}^{2}-F \geq 0$. This can be rewritten as $\frac{1}{2} p_{E}^{2 e} \geq F$. If the fixed cost is higher than this, we need to analyse equilibria in which a fraction only of agents invest. We do this in appendix IV. The analysis and results are not qualitatively different so we focus here on the case where all agents invest.

Using the budget constraint and the first-order conditions above, the typical demand by agents in the emerging economy for shares of a domestic project $\left(s_{E E}\right)$ and for shares of an industrialized country project $\left(s_{E I}\right)$ are given by:

$$
\begin{aligned}
s_{E E}= & \frac{\beta Y_{E}}{1+\beta} \frac{1}{L p_{E}}\left[z_{E}+\phi_{\text {out }} z_{I}\left(p_{E} / p_{I}\right)^{1 / \rho-1}\right]^{-1} \\
& \text { and } \\
s_{E I}= & \frac{\beta Y_{E}}{1+\beta} \frac{\left(1+\tau_{\text {out }}\right)^{-1 / \rho}}{L p_{I}}\left(p_{E} / p_{I}\right)^{1 / \rho-1}\left[z_{E}+\phi_{\text {out }} z_{I}\left(p_{E} / p_{I}\right)^{1 / \rho-1}\right]^{-1}
\end{aligned}
$$

where $\phi_{\text {out }}=\left(1+\tau_{\text {out }}\right)^{1-1 / \rho}$ is a transformation of transaction costs on purchases of assets of the industrialized country. As $\rho<1$, we interpret an increase in $\phi_{\text {out }}$ as a reduction in transaction costs on outflows. Note that $0 \leq \phi_{\text {out }} \leq 1$. From a theoretical point of view, it is interesting to note that non-expected utility combined with assets with linearly independent payoffs generates a demand for shares that has the same form as those derived in trade models with transportation costs and DixitStiglitz type preferences. Note also that the demand for individual shares increases with income, and decreases with the total number of projects/assets. Finally, demand for foreign shares decreases with transaction costs on international trade in assets. Even for identical asset prices, a home bias will emerge in asset demands.

Projects have a fixed unit size and population is equal in each country ${ }^{11}$, so that the equilibrium

\footnotetext{
${ }^{11}$ We discuss the consequences of different population size in appendix VI.
} 
on each stock market (inclusive of those shares that serve to pay the transaction costs) implies for a specific asset/project:

$$
\begin{aligned}
1 & =\frac{1}{p_{E}} \frac{\beta}{1+\beta}\left(\frac{Y_{E}}{z_{E}+z_{I} \phi_{\text {out }} q^{1 / \rho-1}}+\frac{Y_{I} \phi_{\text {in }} q^{1-1 / \rho}}{z_{I}+z_{E} \phi_{\text {in }} q^{1-1 / \rho}}\right) \\
1 & =\frac{1}{p_{I}} \frac{\beta}{1+\beta}\left(\frac{Y_{I}}{z_{I}+z_{E} \phi_{\text {in }} q^{1-1 / \rho}}+\frac{Y_{E} \phi_{o u t} q^{1 / \rho-1}}{z_{E}+z_{I} \phi_{\text {out }} q^{1 / \rho-1}}\right)
\end{aligned}
$$

where $\phi_{i n}=\left(1+\tau_{i n}\right)^{1-1 / \rho}<1$ and $q=p_{E} / p_{I}$ is the relative price of assets between emerging and industrialized markets. These two equations give the equilibrium conditions on the stock market for a typical asset in the emerging market and a typical asset in the industrialized market. There are $L\left(z_{E}+z_{I}\right)$ such equilibrium conditions. In the parenthesis, the first term represents the demand coming from domestic agents and the second term the demand coming from foreigners (inclusive of the transaction costs). Note that these equations imply a financial home-market effect, in the sense that local income will have a more important impact on the local asset market than foreign income, as long as $\phi_{\text {out }}$ and $\phi_{\text {in }}$ are less than 1, i.e. as long as some transaction costs exist ${ }^{12}$.

The stock market equilibrium implies that total world income in the first period is fixed. To see this, note from the stock market equilibrium that: $p_{E} z_{E}+p_{I} z_{I}=\frac{\beta}{1+\beta}\left(Y_{E}+Y_{I}\right)$. Using the optimal investment rule and the definition of world income, we get that $L\left(Y_{E}+Y_{I}\right)=\frac{2 L(1+\beta)}{2+\beta}\left(w_{E}+w_{I}\right)$. Total consumption in the world is given by the world resource constraint $L\left(c_{E}+c_{I}\right)=\frac{2 L\left(w_{E}+w_{I}\right)}{2+\beta}$.

It is useful to rewrite the price of assets in terms of the relative price using the constraint on world income and the asset markets equilibrium. These become:

$$
p_{E}^{2}=\frac{2 \beta\left(w_{E}+w_{I}\right)}{(2+\beta)\left(1+q^{-2}\right)} \quad, \quad p_{I}^{2}=\frac{2 \beta\left(w_{E}+w_{I}\right)}{(2+\beta)\left(1+q^{2}\right)}
$$

This implies that an increase in the relative price of assets corresponds to an increase in investment in the emerging market and a decrease of investment in the industrialized one. The relationships with per-capita income are as follows:

$$
Y_{E}=w_{E}+\frac{\beta\left(w_{E}+w_{I}\right)}{(2+\beta)\left[1+q^{-2}\right]} \quad, \quad Y_{I}=w_{I}+\frac{\beta\left(w_{E}+w_{I}\right)}{(2+\beta)\left[1+q^{2}\right]}
$$

An increase in the relative price of assets in the emerging market is associated with an increase in income in this country.

\subsection{Equilibrium relationship between asset prices and income shares}

We first examine the case of symmetric transaction costs $\left(\phi_{i n}=\phi_{\text {out }}=\phi\right)$. We believe that this is the most empirically relevant case as emerging economies that liberalized capital movements, with

\footnotetext{
${ }^{12}$ It is easy to check that if transaction costs were levied on the dividends in the second period at the level $\tau_{d}$, then $\phi_{\text {out }}=\left(\frac{1+\tau_{\text {out }}}{1-\tau_{d}}\right)^{1-1 / \rho}$ and $\phi_{\text {in }}=\left(\frac{1+\tau_{\text {in }}}{1-\tau_{d}}\right)^{1-1 / \rho_{\text {so }}}$ that the home bias would be even larger.
} 
the objective for example of attracting foreign capital, liberalized both outflows and inflows. We will analyze in Section 5 the case where this liberalization is not fully symmetric.

As world income is fixed, it proves convenient to define $s_{Y}=Y_{E} /\left(Y_{E}+Y_{I}\right)$ as the share of income in the emerging market. Equation (9) of the stock market equilibrium can be rewritten as:

$$
q=\frac{s_{Y} z_{I}\left(1-\phi^{2}\right)+z_{E} \phi q^{1-1 / \rho}+z_{I} \phi^{2}}{z_{I} \phi q^{1 / \rho-1}+z_{E}-s_{Y} z_{E}\left(1-\phi^{2}\right)}
$$

Note that if $\phi=1$ (zero transaction costs) then $q=1$, which implies that without any financial segmentation, the price of assets is identical in the two countries.

There are three equilibrium relations that help us solve the model in the case with positive investment in both countries. These are the income equation (2), the optimal investment equation (5), and the equilibrium on the stock markets (9). By eliminating the optimal investment equation, we can reduce the model to two equilibrium relations between $s_{Y}$ and $q$, the share of income and the relative asset price in the emerging market. From (11), we get immediately the equilibrium income relation, which we call the $Y Y$ schedule:

$$
s_{Y}=\frac{s_{w}(2+\beta)}{2(1+\beta)}+\frac{\beta}{2(1+\beta)\left(1+q^{-2}\right)}
$$

where $s_{w}=w_{E} /\left(w_{E}+w_{I}\right)<1 / 2$, is the share of wage income in the emerging market. The equilibrium $Y Y$ relation says that an increase in the relative asset price $q$ generates an increase in $s_{Y}$, the income share of the emerging market. The reason is that projects are sold at a higher price and more projects are started.

Combining the optimal investment equation with the equilibrium on the stock markets (12), which pins down the equilibrium relative asset price, we get a second relation between $s_{Y}$ and $q$, which we call the $q q$ schedule:

$$
s_{Y}=\frac{\left(q^{2}+\phi q^{1 / \rho}\right)\left(1-\phi q^{-1 / \rho}\right)}{\left(1+q^{2}\right)\left(1-\phi^{2}\right)}
$$

This equilibrium relationship reflects that a higher share of income in the emerging market leads to a higher relative asset price (we show in appendix II that $\partial s_{Y} / \partial q>0$ ). An increase in income in the emerging market leads to an increase in saving which, as long as markets are segmented $(\phi<1)$, falls disproportionately on domestic assets. The increase in demand in turn generates higher asset prices in the emerging market. This mechanism is the financial market size effect identified in Martin and Rey (2001).

On figure 3, we illustrate the equilibrium as the intersection of the $Y Y$ and $q q$ schedules. The important result is that the relative price of assets in the emerging market is always less than 1 as long as the two markets are not perfectly integrated $(\phi \neq 1)$ and $s_{w}<1 / 2$. In appendix III, we show that the two curves only cross once, so that only one "good" equilibrium exists. 


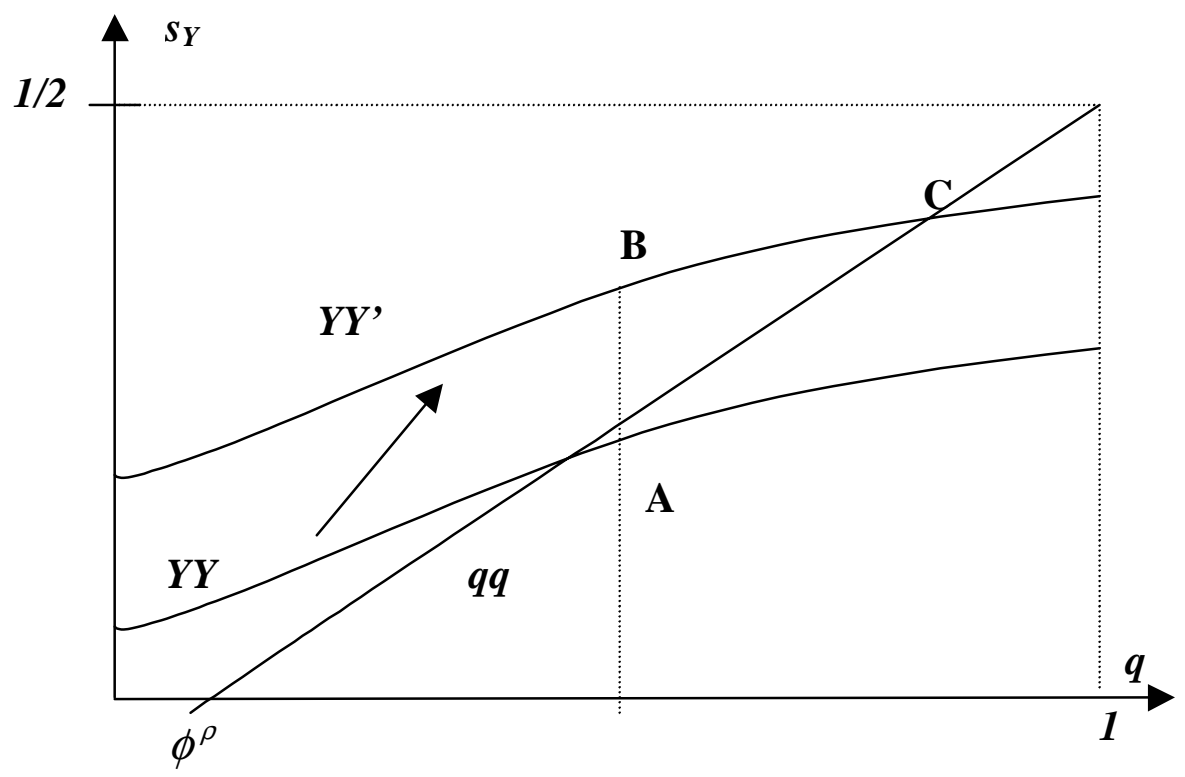

Figure 3: An increase in productivity in the emerging market

The asset price in the emerging market is less than in the industrialized country, the more so, the larger the differential in productivities. Note that this implies that investment in the emerging market will be less than in the industrialized market even though projects have, ex-ante, the same payoffs. This also implies that as long as international financial markets are segmented, the differential in productivity will be magnified by differential investment $\left(s_{Y}<s_{w}<1 / 2\right)$. To see this graphically, suppose $w_{E}$ increases. This shifts up the $Y Y$ curve. The increase in income in the emerging market comes in two parts. The direct effect increases the income share from $A$ to $B$ while the increase in the asset price of the emerging market further increases the income share from $B$ to $C$. The magnification effect comes from the increased investment and wealth effect induced by the increase in asset price.

If financial markets $(\phi=1)$ were perfectly integrated, the $q q$ curve would be vertical at $q=1$. In such a case, an increase in the wage level of the emerging market, a shift of the $Y Y$ curve has no effect on the relative asset prices and therefore would have no amplification effect on relative income.

\subsection{Financial globalization and asset prices}

We now analyze the impact of a decrease in transaction costs on international trade in assets which causes $\phi$ to rise. The effect of an increase in $\phi$ on the $q q$ curve can be seen by examining how $s_{Y}$ is affected by an increase in $\phi$ for a given $q$ : 


$$
\frac{\partial s_{Y}}{\partial \phi}=\frac{\left(1+\phi^{2}\right)\left(q^{1 / \rho}-q^{2-1 / \rho}\right)-2 \phi\left(1-q^{2}\right)}{\left(1+q^{2}\right)\left(1-\phi^{2}\right)^{2}}
$$

This expression is negative as long as $q<1$ that is as long as $s_{w}<1 / 2$. The symmetric decrease in transaction costs is illustrated in figure 5 and implies a rightward shift of the $q q$ curve. The $Y Y$ curve, meanwhile, is unaffected.

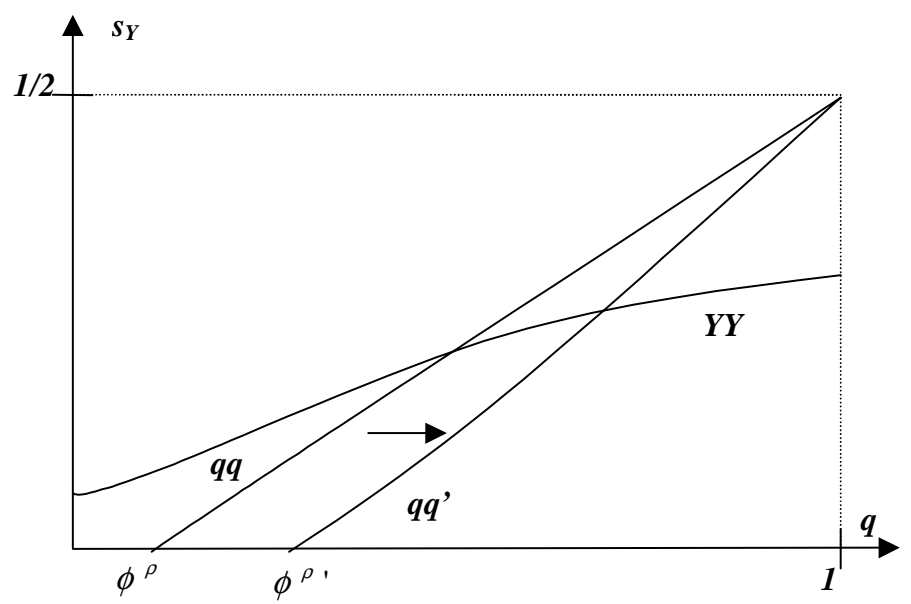

Figure 4: A symmetric decrease in transaction costs

The fall in transaction costs causes both the income share in the emerging market and the relative price of assets to increase. The intuition is that lower transaction costs on international trade in assets attract foreign investment as the price of a typical asset in the emerging market is lower than one on the industrialized market, even though the assets are identical ex-ante. Lower transaction costs on trade in assets also enable both countries to engage in more inter-temporal $\operatorname{trade}^{13}$ : the richer industrialized country can lend more to the emerging market. This explains why the relative demand for the assets of the emerging market rises. As the asset price in the emerging market becomes higher, the incentive to invest in that country is strengthened, so that income increases further, as does the domestic demand for assets in the emerging market.

\subsection{Financial globalization and the current account}

It is interesting to investigate the impact of financial globalization on the first period current account of the emerging market in our setting. The current account is the difference between the country's production and its investment and consumption :

\footnotetext{
${ }^{13}$ As noted in the introduction, this is the reason for the opposite effect of lower transaction costs from the new trade and geography models.
} 


$$
C A_{E}=L\left(w_{E}-\frac{1}{2} z_{E}^{2}-c_{E}\right)=L \frac{\beta}{1+\beta}\left(\frac{w_{E}-w_{I} q^{2}}{1+q^{2}}\right)
$$

It is easy to check from (13) and (14) that if $\phi=0$, then $q^{2}=w_{E} / w_{I}$ so that the current account is balanced. As $q^{2}$ increases with lower transaction costs and is always higher than $w_{E} / w_{I}$ when $\phi>0$, the current account of the emerging market is in deficit. The current account deficit of the emerging market increases with lower transaction costs on trade in assets (higher $\phi$ ). This is consistent with the previous section where we showed that liberalizing capital movements would generate higher relative asset prices in the emerging market. The capital inflows generated by such liberalization are just the mirror image of the adjustment in prices. Capital inflows are larger than outflows as agents in the industrialized economy take advantage of the lower asset prices in the emerging market. This is made easier as transaction costs between the two markets decrease.

\subsection{Financial globalization and market incompleteness}

In the "good" equilibrium financial globalization alleviates market incompleteness, thus reduces the volatility of consumption in the second period. The reason is that the total number of assets increases as transaction costs decrease. The total number of assets is $Z^{w}=L\left(z_{E}+z_{I}\right)=L\left(p_{E}+p_{I}\right)$. It can easily been shown that the total number of assets is increasing in $q$ so that $\partial Z^{w} / \partial \phi>0$. This just comes from the convexity of the investment cost function: as the price of assets increases in the emerging market with lower transaction costs, the number of assets in the emerging market increases more than it decreases in the industrialized country. From that point of view, financial globalization is stabilizing. However, this is when "things go well" that is when agents are optimistic about investment prospects in the emerging market. In the next Section, we analyze a case when "things go wrong". In this case, financial globalization can become destabilizing.

\section{Self-fulfilling expectations and financial integration: when things go wrong}

Until now, we have focused on equilibria in which both countries invest in a positive number of projects. However, the decision to invest at the beginning of the period depends crucially on the expected price of assets at the end of the period when the stock markets open and shares in the projects are traded. The expected asset price (which can be interpreted as the inverse of the cost of capital) determines whether investment is profitable. We now investigate under what condition a crash driven by selffulfilling expectations can occur. In particular, we are interested in the impact of transaction costs on this possibility. We ask the following question: under which conditions, can a rational expectations equilibrium exists in which agents in the emerging market do not invest? Or to put it another way, when is the expected price low enough that a single agent will find it unprofitable to invest? The condition for this to happen is that $\pi_{E}^{e}=p_{E}^{e} \widetilde{z}_{E}-\frac{1}{2} \widetilde{z}_{E}^{2}-F \leq 0$ which implies that the profitability 
condition is not fulfilled or that no agent will deviate from the zero-investment equilibrium. $\widetilde{z}_{E}$ in this condition is the investment that would be done by a single "pessimistic" agent if she anticipates that no other single agent will invest (so $L z_{E}^{e}=0$ ). The optimal investment rule $\widetilde{z}_{E}=p_{E}^{e}$ still applies here. This agent is small ( $L$ is large) so that her decision does not affect aggregate income or investment.

Suppose that $z_{E}^{e}=0$. Aggregate income in the emerging market is $L Y_{E}^{e}=L w_{E}$ as expected wealth goes to zero. As world income is fixed, expected income in the industrialized country increases by the amount it falls in the emerging market. This expected change in the distribution of world income is important because it determines the expected relative demands for assets in the emerging and industrialized economies. Using the stock market equilibrium (9) in this case, it can be checked that the expected relative asset price when agents in the emerging market are pessimistic is:

$$
q^{e}=\left\{\frac{s_{w}(2+\beta)\left(\frac{1}{\phi}-\phi\right)+2(1+\beta) \phi}{2(1+\beta)}\right\}^{\rho}
$$

Note that the expected relative price in this case decreases with financial globalization (higher $\phi)$ at low levels of $\phi$ and then increases at high levels of financial globalization. The profitability of investing in projects is:

$$
\pi_{E}^{e}=\frac{\beta}{2+\beta}\left(w_{E}+w_{I}\right) q^{e 2}-F
$$

The condition for the zero-investment equilibrium to exist can be rewritten using equations (17) and (18):

$$
\pi_{E}^{e}=\frac{\beta\left(w_{E}+w_{I}\right)}{2+\beta}\left[\frac{s_{w}(2+\beta)\left(\frac{1}{\phi}-\phi\right)+2(1+\beta) \phi}{2(1+\beta)}\right]^{2 \rho}-F<0
$$

The profit function is U-shaped as a function of $\phi$ and so inequality (20) can be satisfied for intermediate levels of transaction costs.

For multiple equilibria to exist, it must be that for a given set of parameter values, a "good" equilibrium exists when $z_{E}^{e}>0$ and does not exist when $z_{E}^{e}=0$. If $F$ is large enough, there will always be a set of intermediate transaction costs for which the zero-investment equilibrium exists. From (20) it can be checked that the zero-investment equilibrium cannot occur without capital flows $(\phi=0)$ or with perfect capital mobility $(\phi=1)$. This is intuitive. In a situation of financial autarky, agents can only save by buying domestic assets. This puts a floor on the demand for domestic assets and hence on their expected price as capital flight is impossible. In a situation of perfect capital mobility, $q=1$, so arbitrage implies that agents in the industrialized country would rush to buy the assets in the emerging market in the event of a crash. This rules out a crash on asset prices in the emerging market. In this case, if it is profitable to invest in the industrialized country it must be so also in the emerging market. Another way to say this is that a global financial crash is not possible. This is the same reasoning as for the impossibility of a crash in autarky. 
The possibility of multiple equilibria and its dependence on transaction costs is illustrated in figure 5.The profit functions are depicted for both countries and both types of expectations, pessimistic and optimistic. The $\pi_{I}^{e}\left(z_{E}^{e}>0, z_{I}^{e}>0\right)$ schedule shows the dependence of asset prices in the industrialized country on transaction costs in the good ("optimistic") equilibrium. It decreases as transaction costs are lowered as asset prices in the industrialized country and in the emerging market converge. The inverse happens with the $\pi_{E}^{e}\left(z_{E}^{e}>0, z_{I}^{e}>0\right)$ schedule which illustrates that profits in the emerging market increase with lower transaction costs. The $\pi_{E}^{e}\left(z_{E}^{e}=0\right)$ schedule shows the dependence of profit in the emerging market on transaction costs in the "pessimistic" case. If we choose the fixed $\operatorname{cost} F$ such that in the case of multiple equilibria, the good equilibrium is characterized by all agents investing then the zero profit frontier is given by the dashed horitontal line. In this case, multiple equilibria arise for the emerging market between $\phi_{1}$ and $\phi_{2}$. If the fixed cost is higher, the "good" equilibrium in the emerging market is one where only a fraction of agents invest and multiple equilibria arise for a larger set of transaction costs (the zero profit line is shifted upward). If the fixed cost is lower, the area of multiple equilibria shrinks.

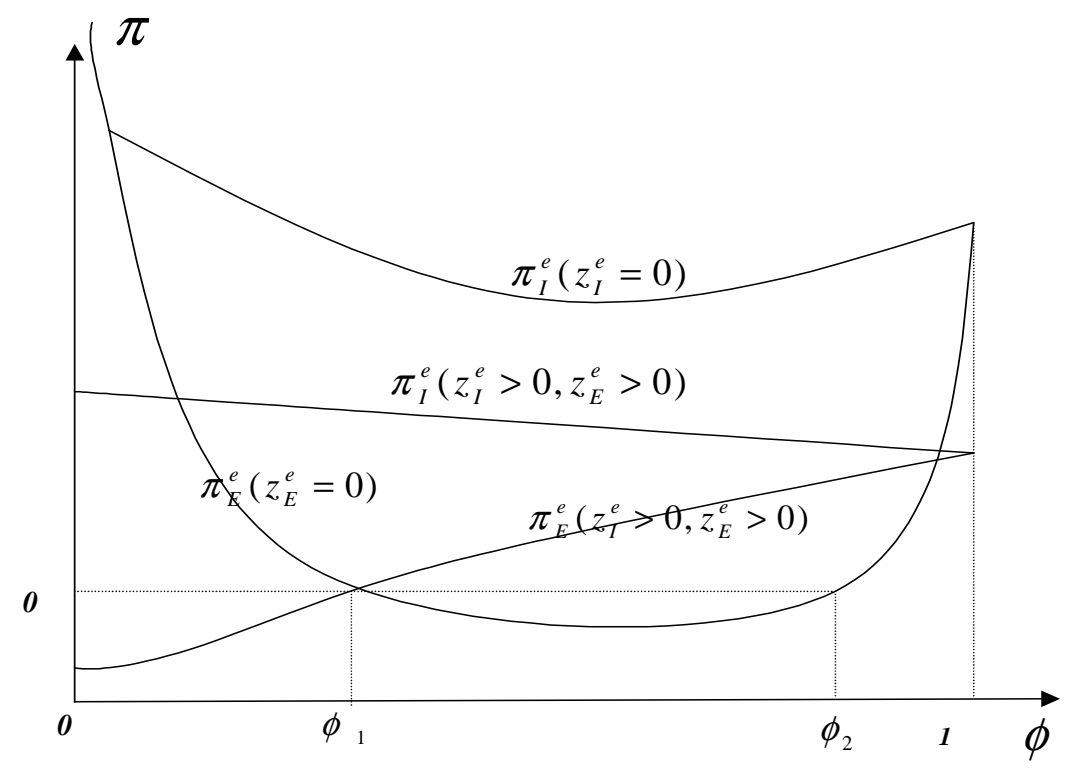

Figure 5: Multiple equilibria and transaction costs

As is usual in models with multiple equilibria, circular causation is at work here. If agents believe that other agents will undertake no project, they then expect aggregate income in the emerging market at the end of the period to be low. Lower expected income entails a lower demand for assets. When financial markets are segmented and assets are imperfect substitutes, then this fall of demand of 
assets will fall disproportionately on local assets. This in turn generates a low relative asset price in the emerging market. This is a home bias effect. Finally, the optimal investment rule says that investment depends positively on the expected asset price which we can interpret as the inverse of the cost of capital.

The circular causality mechanism has common features with the agglomeration phenomena described in the "new economic geography" literature. Here, we could talk of an "agglomeration of expectations" which produces a coordination failure. However, the stability properties are different: in our model, the "good" equilibrium is always stable, whereas in the "new economic geography" literature, a fundamental result is that the symmetric equilibrium becomes unstable for sufficiently low transaction costs.

Is the emerging market more vulnerable to a financial crash than the industrialized economy? To answer this question we can compare the profit level of a single "pessimistic" investor in the emerging market $\left(z_{E}^{e}=0\right)$ given in equation (18) to its analog in the industrialized country $\left(z_{I}^{e}=0\right)$. It can be checked that the $\pi_{I}^{e}\left(z_{I}^{e}=0\right)$ function is the same as in equation (18) except for the term in $s_{w}$ which is replaced by $1-s_{w}$. One can see readily that $\pi_{I}^{e}\left(z_{I}^{e}=0\right)>\pi_{E}^{e}\left(z_{E}^{e}=0\right)$ as long as $\phi<1$, so that the "pessimist" profit function of the industrialized country is always higher than the one for emerging market as illustrated in figure 5. Moreover, for the level of fixed cost such that multiple equilibria become possible in the emerging market, the industrialized country cannot have a crash $^{14}$. This is because it is possible to show that $\pi_{I}^{e}\left(z_{I}^{e}=0\right)>\pi_{I}^{e}\left(z_{I}^{e}>0, z_{E}^{e}>0\right)>\pi_{E}^{e}\left(z_{I}^{e}>0, z_{E}^{e}>0\right)$ for all levels of transaction costs. In this case, multiple equilibria in a world of countries with identical productivities $\left(s_{w}=1 / 2\right)$ are not possible either.

The reason for the lower vulnerability of the industrialized economy to financial crashes, is that the demand for assets in that market even when depressed by pessimistic expectations is always higher than in the emerging market. This in turn implies a higher price for assets and higher profitability on the industrialized country asset market even when bad times are expected: the industrialized country can never be as pessimistic about its own income level and therefore its asset prices as the emerging market.

How do fundamentals affect the possibility of a financial crash? For a given distribution of wage income (a given $s_{w}$ ), equation (20) shows that when "world" productivity and wage levels $\left(w_{E}+w_{I}\right)$ are high, the profit function of a single "pessimistic" agent is higher and therefore the set of parameters for which a financial crash is possible is smaller. The reason is that greater world income generates a higher demand for shares, irrespective of expectations, which partially will benefit the emerging market.

Also, fundamentals in the emerging market are important. For given world fundamentals $\left(w_{E}+w_{I}\right)$,

\footnotetext{
${ }^{14}$ The maximum number of equilibria is 2 in this case. This is because if $F \leq F_{1}=\frac{\beta w_{E}}{2+\beta}$, the "good" equilibrium is such that all agents invest in the emerging market and it is possible to show that the $Y Y$ and $q q$ curves only cross once. If $F>F_{1}$, then the "good "equilibrium is such that not all agents invest. This equilibrium is also unique (see appendix IV).
} 
a higher productivity and wage level in the emerging market (a higher $s_{w}$ ) will increase the profit level of a "pessimistic" agent as we know $\phi<1$. The reason is that higher local income will generate higher demand for shares, which because of transaction costs on capital flows, will disproportionately favor shares of the emerging market. Note that this negative relation between income per capita and the vulnerability to crashes only appears when countries are sufficiently open to capital movements, a fact that accords with the two graphs we present in introduction.

The financial crash in the emerging market is characterized by low asset prices, investment, income and consumption (both in first period and in second period). Per-capita income in the emerging market is lower in the case of a financial crash $\left(w_{E}\right)$ than in autarky $\left(2(1+\beta) w_{E} /(2+\beta)\right)$. This level is itself the lowest for the emerging market among all "good" equilibria with positive investment. Also, contrary to what occurs in the "good" equilibrium, in the event of a crash, the emerging country experiences a current account surplus, basically because it has no assets to sell. In this case, we can also characterize the financial crash as a situation of capital flight since the only assets that agents can buy to save and diversify risk are foreign.

These characteristics of the crash fit the stylized facts of the emerging markets. In particular, investment in our model is the component which is hit the hardest, consistent with the findings of Tornell and Westermann (2001). They also find that the bust is followed by a recession. Other authors have insisted on the fall in asset prices that are typically the starting point of the crisis and the reversal in the current account situation.

We have seen that "when things go well", financial globalization decreases the volatility of secondperiod consumption as it decreases market incompleteness measured by $\left(N-L z_{E}-L z_{I}\right)$. Obviously, when investment crashes in the emerging market the number of assets falls in that country. To see how the number of assets at the world level is affected by the crash, we compare the extent of market incompleteness in the case of a financial crash $\left(z_{E}=0\right)$ to the measure of market incompleteness in the non crash equilibrium in financial autarky $(\phi=0)$, which we know is the situation where market incompleteness is at its maximum for the "good" equilibrium. The total number of assets in the later situation is higher than in a situation of financial $\operatorname{crash}^{15}$. Hence, market incompleteness is higher in the situation of the financial crash than in the situation of financial autarky. This implies that in a crash not only income and consumption levels are lower but volatility of second-period consumption is also higher.

The introduction of riskless and low return projects would make a crash possible even in autarky. In such circumstances, if agents expect that no high return risky investment projects will be implemented and that agents will substitute to low return riskless projects, they expect aggregate income, demand for assets of the risky projects and their relative price to be low. In effect, the possibility of an alternative form of domestic investment with low return would be similar to the possibility of capital

\footnotetext{
${ }^{15}$ In financial autarky the total number of assets is $L[2 \beta /(2+\beta)]^{1 / 2}\left(w_{E}^{1 / 2}+w_{I}^{1 / 2}\right)$. In a crash, it falls to $L[2 \beta /(2+$ $\beta)]^{1 / 2}\left(w_{E}+w_{I}\right)^{1 / 2}$.
} 
flight in our model. This would resemble the logic of the model of Murphy, Schleifer and Vishny (1989). As long as the cost of riskless investments is not too high, a crash of prices of risky investment projects would be possible, even in autarky. However, facilitating the purchase of foreign assets with high return would still increase the possibility of a financial crash, albeit one of a different nature: agents in the emerging market would substitute into risky high-return foreign assets in place of riskless low-return domestic assets. The emerging market would still be more vulnerable to this type of crash than the industrialized country: in the pessimistic case, its income and therefore demand for domestic assets would still fall more than those of the industrialized country.

\section{A symmetric financial liberalization}

\subsection{A symmetric transaction costs and the "good" equilibrium}

Our framework allows us to distinguish between transaction costs on financial inflows and outflows, so that we can analyze the impact of asymmetric liberalization policies. In the case of asymmetric transaction costs, the $Y Y$ schedule, (equation 13) still applies. The $q q$ schedule that defines the stock market equilibrium is however altered in the following way:

$$
s_{Y}=\frac{\left(q^{2}+\phi_{\text {out }} q^{1 / \rho}\right)\left(1-\phi_{\text {in }} q^{-1 / \rho}\right)}{\left(1+q^{2}\right)\left(1-\phi_{\text {in }} \phi_{\text {out }}\right)}
$$

The impact of a decrease in transaction costs on inflows (an increase in $\phi_{i n}$ ) is shown on figure 6 as a rightward shift of the modified $q q$ curve (see appendix $\mathrm{V}$ for the proof). To compare the impact of symmetric and asymmetric financial globalization, we have depicted both types on the same graph. Starting from a situation with identical transaction costs on inflows and outflows (point $A$ ), a symmetric decrease in transaction costs leads to point $B$ which implies an increase in both $q$ and $s_{Y}$, if $w_{I}>w_{E}$. A decrease in transaction costs on inflows, will shift the equilibrium to point $C$, implying a larger increase in both $q$ and $s_{Y}$ than in the symmetric case ${ }^{16}$.

It is easy to check that a decrease in transaction costs on outflows shifts the modified $q q$ curve on the left as shown on figure 7. Both the asset price and the income level decrease because lower transaction costs on outflows induce domestic agents in the emerging market to switch from domestic to foreign assets. Note that contrary to the case of symmetric liberalization, the sign of the impact of asymmetric liberalization on asset prices and income share does not depend on the difference in wage rates.

\footnotetext{
${ }^{16}$ Claessens and Rhee (1994) find evidence of a positive relation between a stock's P/E-ratio and its accessibility by foreign investors for most emerging markets, suggesting that barriers to access by foreigners have a negative impact.
} 


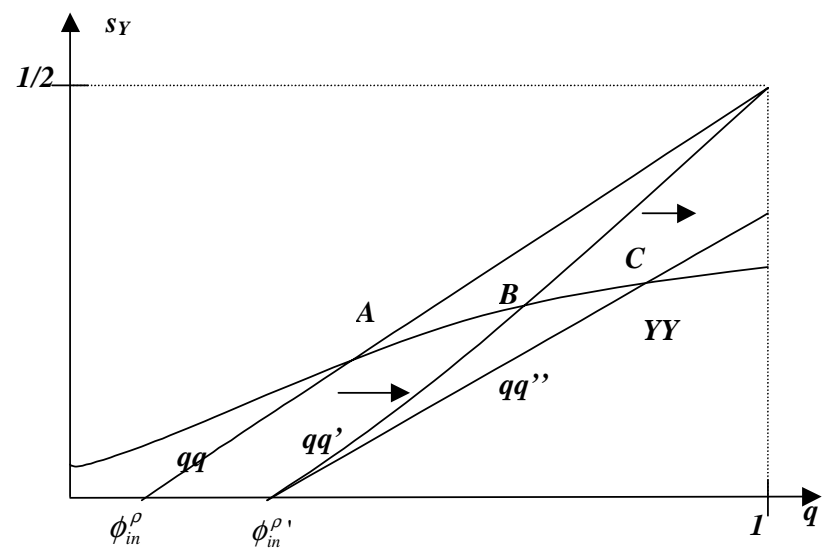

Figure 6: A decrease in transaction costs on inflows

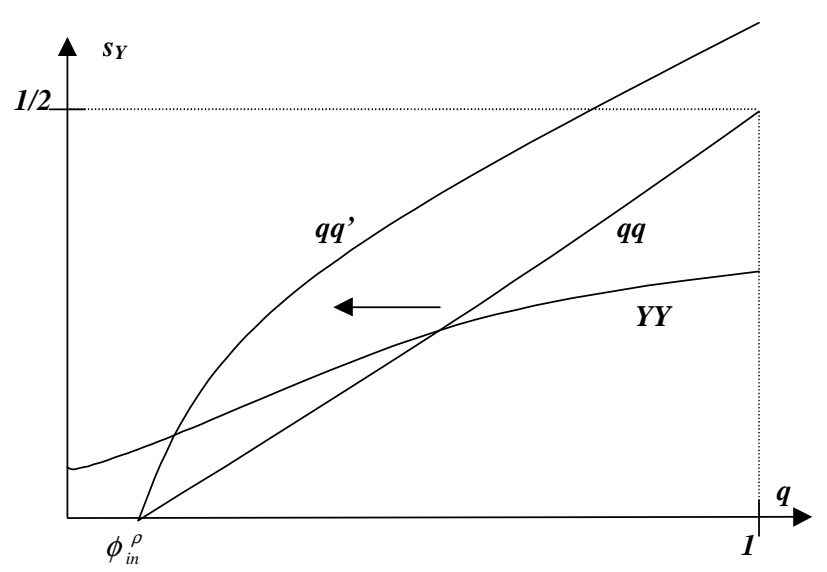

Figure 7: A decrease in transaction costs on outflows 


\subsection{A symmetric transaction costs and financial crashes}

We can perform the same analysis as in section 4 and analyze how asymmetric transaction costs affect the possibility of a financial crash driven by self-fulfilling expectations. The condition for the zero-investment equilibrium to exist becomes:

$$
\frac{\beta\left(w_{E}+w_{I}\right)}{2+\beta}\left[\frac{s_{w}(2+\beta)\left(\frac{1}{\phi_{o u t}}-\phi_{i n}\right)+2(1+\beta) \phi_{i n}}{2(1+\beta)}\right]^{2 \rho}-F<0
$$

Hence, quite intuitively, a combination of low transaction costs on outflows and high transaction costs on inflows makes it easier to have a zero-investment equilibrium where a "pessimistic" agent does not expect it to be profitable to start investment projects.

\section{Domestic and international financial liberalization}

\subsection{Domestic transaction costs and the "good" equilibrium}

We can also use our model to analyze how the interaction of domestic and international financial liberalization affect asset prices and investment. To do this, we introduce a new type of transaction costs on financial markets of the emerging country. On top of the transaction costs on inflows and outflows (which are again identical), agents in the emerging market, when they buy domestic assets pay a domestic transaction cost, which also takes the form of an iceberg cost. This may be thought as a proxy for domestic financial under-development. We assume that no such transaction cost hampers the domestic market in the industrialized country so that we depart from the rest of the paper where the only difference between the two countries was their productivity level. We call $\phi_{D}$, the transformation

of domestic transaction costs: $\phi_{D}=\left(1+\tau_{D}\right)^{1-1 / \rho}$, where $\tau_{D}$ is the domestic transaction cost which we assume is lower than the international transaction cost so that $\phi_{D}>\phi$. The model is unchanged except for the stock market equilibrium conditions which become:

This just says that higher domestic transaction costs reduce asset demand from domestic agents. The $q q$ schedule now becomes:

$$
s_{Y}=\frac{\left(\phi_{D} q^{2}+\phi q^{1 / \rho}\right)\left(1-\phi q^{-1 / \rho}\right)}{\left(1+q^{2}\right)\left(\phi_{D}-\phi^{2}\right)}
$$

Hence, a decrease in domestic financial transaction costs shifts the $q q$ curve to the right and induces an increase in asset prices, investment and income. The working is qualitatively the inverse of the one shown in figure 8. This is not surprising as an increase in transaction costs on outflows and a decrease in domestic transaction costs both lead to an increase of demand of assets by domestic agents. 


\subsection{Domestic transaction costs and financial crashes}

The introduction of domestic transaction costs makes it easier to get the zero-investment equilibrium. The reason is that by decreasing demand for domestic assets it decreases further the relative expected asset price and therefore expected profitability of investment projects when agents are pessimistic. To see this, we derive the expected profit when agents in the emerging market are "pessimistic":

$$
\frac{\beta\left(w_{E}+w_{I}\right)}{2+\beta}\left[\frac{s_{w}(2+\beta)\left(\frac{\phi_{D}}{\phi}-\phi\right)+2(1+\beta) \phi}{2(1+\beta)}\right]^{2 \rho}-F<0
$$

The expected profit is lower, the higher the domestic transaction costs (the lower $\phi_{D}$ ). Hence, lower transaction costs on domestic markets in the emerging market will reduce the parameter set for which zero-investment equilibrium driven solely by self-fulling expectations is possible.

\section{Welfare implications}

The welfare implications are numerous and complex. In the previous sections, we have seen that lowering transaction costs on asset trade had consequences on: real resources lost in the transaction, relative asset prices, investment and income and therefore consumption in both first and second period, the degree of market incompleteness and therefore the volatility of consumption in second period. Lowering transaction costs on trade in assets could also move the emerging market in a totally different situation characterized by a financial crash driven by self-fulfilling pessimistic expectations. We first analyze the welfare impact of lower transaction costs in the "optimistic" case with positive investment in both countries. The level of utility of an agent in the emerging market is given by the following expression:

$$
U_{E}=C+(1+\beta) \ln Y_{E}+\beta\left[\frac{\rho}{(1-\rho)}-1\right] \ln p_{E}+\frac{\beta \rho}{1-\rho} \ln \left[1+\phi_{\text {out }} q^{1 / \rho-2}\right]
$$

where $C$ is a constant. There are three distinct effects of lowering transaction costs on international asset trade that can be identified in the three last terms of the above equation: 1) an income effect: For the emerging market, we know it will be a positive effect for a symmetric decrease of transaction costs on inflows and outflows and for a decrease of transaction costs on inflows. It will be negative on income in the case of a decrease of transaction costs on outflows. 2) a price effect: the price of assets of the emerging market will follow the same pattern as income. However, the welfare effect may be different. On the one hand, for a given income, higher prices in the emerging market imply lower demand for those assets which lowers welfare. On the other hand, higher asset prices in the emerging market generate higher investment and a higher number of assets and therefore more diversification possibilities. If $\rho>1 / 2$, so that agents are "very" risk averse, the increase in diversification possibility will be highly valued and an increase in $p_{E}$ will increase welfare. 3) a direct effect: with lower 
transaction costs on outflows (higher $\phi_{\text {out }}$ ), it becomes less costly to diversify. Hence, this effect is always positive.

We will not be able to analytically derive the welfare impact of decreasing transaction costs on trade in asset for all levels of transaction costs. However, we can evaluate welfare impacts of liberalization of capital flows around the autarky equilibrium and the perfect capital mobility equilibrium. For example, an asymmetric decrease of transaction costs around the autarky situation has the following impact on utility in the emerging economy:

$$
\underset{\substack{\partial \phi_{\text {out }} \\ \phi_{\text {out }}=\phi_{\text {in }}=0}}{\frac{\partial U_{E}}{(2+\beta)(1-\rho)}}\left[(2+\beta)\left(\frac{w_{E}}{w_{I}}\right)^{1 / \rho-2}-(1+\beta)\left(\frac{w_{E}}{w_{I}}\right)^{1 / \rho-2}\right]
$$

As $w_{E}<w_{I}$, it implies that if $\rho \geq 1 / 2$, then the expression above is always positive and utility increases with liberalization of capital outflows ${ }^{17}$. The intuition is that in this case of high risk aversion, the possibility to diversify at a lower cost is highly valued by agents of the emerging market. If $\rho<1 / 2$ and the wage difference is sufficiently large, then the negative income effect dominates and the utility of agents in the emerging market will decrease. Evaluated in the perfect capital mobility equilibrium, the impact of imposing restrictions on capital outflows would always be negative for welfare as:

$$
\frac{\partial U_{E}}{\partial \phi_{\text {out }}}=\frac{\beta(1+\rho)}{4(1-\rho)}
$$

The impact of a decrease in transaction costs on inflows on welfare evaluated at autarky is given by:

$$
\underset{\substack{\partial \phi_{i n} \\ \phi_{\text {out }}=\phi_{\text {in }}=0}}{\frac{\partial U_{E}}{(2+\beta)(1-\rho)}\left(\frac{w_{E}}{w_{I}}\right)^{-1 /(2 \rho)-1}}
$$

which is always positive. This is also the case when evaluated in the perfect capital mobility case.

The impact of a symmetric decrease in transaction costs on inflows and outflows on welfare evaluated at autarky is given by:

$$
\frac{\partial U_{E}}{\partial \phi}=\frac{\beta \rho}{(1-\rho)}\left(\frac{1+\beta}{2+\beta} q^{-1 / \rho}+\frac{1}{2+\beta} q^{1 / \rho-1}\right)
$$

which is always positive ${ }^{18}$. This is also the case when evaluated at $\phi=1$. This is not surprising as we know that all effects described above are positive in this case for the emerging market.

These results on welfare are valid only for the "good" equilibrium and as usual in models with possible multiple equilibria, we cannot say anything definitive about welfare. In cases where the crisis equilibrium is a possible equilibrium we can however show that if the emerging market falls in the crisis

\footnotetext{
${ }^{17}$ Note that if the two countries have equal wages, the utility always increases with liberalization of capital flows.

${ }^{18}$ It can be shown that, despite its negative impact on its income, this is also true for the industrialized country.
} 
equilibrium its welfare is always less than in the "good" equilibrium at the same level of transaction cost. This is obvious as the crisis equilibrium implies lower income and therefore less consumption (in both periods) and more market incompleteness (as measured by the difference between the number of states and the number of assets) and therefore more second-period consumption volatility. However, it is impossible to give a definitive answer to the question: should emerging economies liberalize capital movements, say in a symmetric fashion (an increase in $\phi$ )?. We know that if they could, they should go all the way to perfect capital mobility $(\phi=1)$, because in this case income in the emerging market is maximized, market incompleteness is minimized and financial crash cannot occur. However, our view is that transaction costs always hinder international trade in assets (due to difference in regulations, cost of acquiring information, exchange rate movements...) even without government imposed transaction costs. We can answer a more limited but relevant question: is welfare in the emerging economy higher in the autarky equilibrium or in the crisis equilibrium? The difference between the two levels of welfare is given by:

$$
U_{E}(\phi=0)-U_{E}(\text { crisis })=(1+\beta) \ln \left[\frac{2(1+\beta)}{2+\beta}\right]+\frac{\beta(2 \rho-1)}{2(1-\rho)} \ln s_{w}-\frac{\beta \rho}{1-\rho} \ln \phi
$$

where parameters (in particular the level of transaction costs) must be such that a crisis is a possible equilibrium. The first term of the expression is positive and reflects the fact that income is higher in autarky than in crisis with capital movements. The last term is negative and reflects the welfare gain of being able to better diversify by purchasing foreign assets even in a financial crash. The second term has an ambiguous sign and reflects the fact that in a crisis equilibrium there are more assets to buy than in autarky but which must be purchased at a higher price. If agents are sufficiently risk averse (high $\rho$ ) they will value this and therefore the expression is negative. When we evaluate this expression at levels of $\phi$ for which a financial crash is possible (that is between the two roots of the quadratic expression 23), we find that the sign is ambiguous. In particular, if agents are not too risk averse (low $\rho$ ) welfare can be higher in autarky than in the financial crisis equilibrium. This is because in this case the welfare gain of being able to buy foreign assets is not valued very much and the loss of income in the financial crash situation is what matters most. For the industrialized country, the welfare impact of a crash in the emerging market has an ambiguous effect on welfare. The reason is that even though its income rises because of the inflows of capital coming from the emerging market, its diversification opportunities decrease as the total number of assets decreases. For $\rho=1 / 2$, for example, it is easy to check that the income effect dominates. For high coefficients of risk aversion, however, the loss in diversification opportunities may dominate.

Again, our implications for welfare should be taken with caution as we can not say which equilibrium will prevail. Hence, our model can only point to the conclusion that financial globalization carries benefits and risks in terms of welfare for emerging markets.

\section{Conclusion}


Under which conditions can financial globalization be held responsible for the recent series of financial crashes in emerging markets? In answering this question, the existing literature has insisted on the fact that financial globalization, because it makes borrowing on world financial markets easier and less costly, may strengthen the potential danger of market failures prevalent in emerging markets: in particular, moral hazard and credit constraints have been shown to facilitate the advent of financial crisis driven by self-fulfilling expectations. In this paper, we show that the existence of such market failures is not a necessary condition for emerging markets to become vulnerable to a financial crash when capital flows are liberalized. Both the potential benefit of financial globalization (in terms of cost of capital, investment and income) and the higher vulnerability of emerging markets to a financial crash come from the same and unique factor that differentiates emerging markets and industrialized countries in our model: their productivity and income level. The higher vulnerability is not due to bad fundamentals, bad institutions, bad financial markets (credit or liquidity constraints), bad incentives (bailouts) or bad exchange rate regimes. This is not to say of course that these problems do not exist or do not constitute important channels through which financial globalization can make emerging markets more vulnerable to a financial crisis $^{19}$. But it suggests that the risks of liberalization of capital flows for emerging markets are a very general feature.

That financial globalization can make emerging markets more vulnerable to a financial crash under the mere condition that these countries have a lower income than industrialized countries has also potentially important policy implications. The recent literature which has emphasized the key role of credit constraints and moral hazard to explain crashes in emerging markets has logically recommended policies which address the informational and institutional frictions which are at the origin of these credit market imperfections. Among such policies, Mendoza (2001) for example, cites microeconomic policies such as the development of credit bureaus in Mexico. More transparency, better information, better banking regulation have also been recommended. Similarly, currency mismatches in fixed exchange rate regimes have listed as prime suspects in the crises of these countries which has led several countries to switch to floating. Our paper shows that these policies and institutional changes may not be sufficient to prevent crises in intermediate income countries and that financial crises may be a much more general phenomenon in those countries.

One implication of our model is that a clear incentive exists for the government of the emerging market to intervene directly on the stock market with a commitment to buy assets when the price falls below a certain level. These policies have been advocated and implemented during the Asian crisis. However, these guarantees would quite naturally generate moral hazard problems which themselves can be at the origin of a financial crisis (Corsetti, Pesenti and Roubini, 1999). Hence, an interesting possible extension of our model would be to formalize the trade-off between endogenous incentives for government guarantees and moral hazard consequences.

\footnotetext{
${ }^{19}$ The inclusion of credit constraints on investment in our model would reinforce the possibility of a crash as the fall in asset prices would reduce the value of collateral.
} 


\section{Appendix}

$\underline{\text { Appendix I: Description of the data used in figures } 1 \text { and 2: }}$

Calculations are made using monthly US Dollar based stock indices from Bloomberg and with World Bank data in US Dollars. Both series are CPI-adjusted. A "Crash" is defined as a month in which the monthly percent change of the index is at least two standard deviations (based on the entire sample) below the average change in index for all countries. The length of the data varies across countries. There are no countries with data shorter than 24 months. The financially closedopen distinction is taken from various sources with a focus on the capital account. As noted in the literature a 0-1 distinction is not satisfactory, but we believe that the general message of figure 1 and 2 would not be altered with a more subtle quantification. We used primarily the dates for liberalization indicated by Kaminsky and Schmukler (2001). For countries not included in that study we used Bekaert, Harvey and Lundblad (2001), Edison and Warnock (2001) and information contained in the IMF Exchange Arrangements and Exchange Restrictions (various years). Figure 8 gives the list of countries, the stock data availability, the years for which the country is considered closed and open and the respective numbers of crashes.

Appendix II: The characteristics of the $Y Y$ and $q q$ curves

For equation (13), the slope is:

$$
\partial s_{Y} / \partial q=\frac{\beta q}{(1+\beta)\left(1+q^{2}\right)^{2}}>0
$$

For equation (14), the slope is:

$$
\partial s_{Y} / \partial q=\frac{2 q\left(1-\phi q^{-1 / \rho}\right)\left(1-\phi q^{1 / \rho}\right)+\frac{1}{\rho} \phi\left(1+q^{2}\right)\left(q^{1 / \rho-1}+q^{1-1 / \rho}\right)}{\left(1-\phi^{2}\right)\left(1+q^{2}\right)^{2}}>0
$$

Appendix III: The effect of a symmetric decrease in transaction costs

An increase in $\phi$ has always a positive impact on $q$ as long as $q<1$, that is as long as $s_{W}<1 / 2$. To see this, use equilibrium equations (13) and (14) to get $\partial q / \partial \phi$ :

$$
\frac{2 \phi\left\{1-2 s_{w}+\beta\left[1-s_{w}\left(1+q^{2}\right)\right]+\beta\left(1-q^{2}\right)+1-2 s_{w} q^{2}\right\}+2(1+\beta)\left(q^{2-1 / \rho}-q^{1 / \rho}\right)}{4 q(1+\beta)\left(1-\phi q^{-1 / \rho}\right)+\frac{2}{\rho} \phi(1+\beta)\left(q^{1 / \rho-1}+q^{1-1 / \rho}\right)-2 q\left(1-\phi^{2}\right)\left[2 \beta+(2+\beta) s_{w}\right]}
$$

which is positive if $s_{W}<1 / 2$. Combining this with the fact that $\frac{\partial s_{Y}}{\partial \phi}<0$ on the $q q$ curve also proves that the $Y Y$ and $q q$ curves cross only once in the relevant range $(0<q<1)$ so that a unique "good" exists. This is because if the two curves were to cross more than once in the relevant range, they would have to cross three times (the $Y Y$ curve starts over the $q q$ curve and in $q=1$ is below the $q q$ curve if $s_{W}<1 / 2$ ). In this case a downward shift of the $q q$ curve (caused by an increase in $\phi$ ) would 


\begin{tabular}{|c|c|c|c|c|c|c|}
\hline Country (source) & \multicolumn{2}{|c|}{ Stock Data Availability } & \multicolumn{2}{|c|}{ Closed } & \multicolumn{2}{|l|}{ Open } \\
\hline Argentina (KS) & $12 / 1 / 75$ & $5 / 31 / 99$ & $1966-77,83-88$ & 15 & $1978-82,89-01$ & 12 \\
\hline Australia (B B) & $5 / 29 / 92$ & $9 / 28 / 01$ & $1966-83$ & & $1984-01$ & 0 \\
\hline Austria (BB) & $1 / 31 / 92$ & $9 / 28 / 01$ & $1966-80$ & & $1981-01$ & 0 \\
\hline Brazil (KS) & $12 / 1 / 75$ & $5 / 31 / 99$ & $1966-75,80-86$ & 6 & $1976-79,87-01$ & 19 \\
\hline Canada (BB) & $1 / 29 / 60$ & $9 / 28 / 01$ & & & $1966-01$ & 3 \\
\hline Chile (KS) & $12 / 1 / 75$ & $5 / 31 / 99$ & $1966-91$ & 3 & $1992-01$ & 1 \\
\hline Denm ark (KS) & $1 / 1 / 75$ & $4 / 30 / 99$ & $1966-87$ & 0 & $1988-01$ & 0 \\
\hline Ecuador (B B) & $1 / 31 / 94$ & $9 / 28 / 01$ & $1993-96$ & 0 & $97-01$ & 6 \\
\hline Egypt (BB) & $7 / 31 / 92$ & $9 / 28 / 01$ & $1966-01$ & 0 & & \\
\hline Estonia (BB) & $6 / 28 / 96$ & $9 / 28 / 01$ & & & $1994-01$ & 5 \\
\hline Finland (KS) & $1 / 1 / 75$ & $12 / 31 / 98$ & $1966-90$ & 0 & $1991-01$ & 1 \\
\hline France (BB) & $1 / 1 / 75$ & $12 / 31 / 98$ & $1968-85$ & 3 & $1966-67,85-01$ & 0 \\
\hline Iceland (BB) & $12 / 31 / 92$ & $9 / 28 / 01$ & $1966-01$ & 0 & & \\
\hline India (B B) & $1 / 31 / 85$ & $9 / 28 / 01$ & $1966-01$ & 2 & & \\
\hline Indonesia (B B) & $4 / 29 / 83$ & $9 / 28 / 01$ & $1966-95$ & 0 & $1996-01$ & 9 \\
\hline Ireland (KS) & $1 / 1 / 75$ & $12 / 31 / 98$ & $1966-91$ & 1 & $1992-01$ & 0 \\
\hline Israel (BB) & $1 / 31 / 92$ & $9 / 28 / 01$ & $1966-01$ & 1 & & \\
\hline Italy (KS) & $1 / 1 / 75$ & $12 / 31 / 98$ & $1966-82,86-92$ & 2 & $1983-85,93-01$ & 0 \\
\hline Ivory Coast (BB) & $1 / 29 / 99$ & $9 / 28 / 01$ & $1968-01$ & 0 & & \\
\hline Jamaica (BB) & $3 / 31 / 87$ & $9 / 28 / 01$ & $1966-01$ & 3 & & \\
\hline Japan (BB) & $1 / 31 / 73$ & $9 / 28 / 01$ & $1966-78$ & 0 & $1979-01$ & 0 \\
\hline Korea (KS) & $12 / 1 / 75$ & $5 / 31 / 99$ & $1966-92$ & 1 & $1993-01$ & 5 \\
\hline Kuwait (BB) & $4 / 30 / 99$ & $9 / 28 / 01$ & & & $1966-01$ & 0 \\
\hline Latvia (B B) & $1 / 30 / 98$ & $9 / 28 / 01$ & & & $1994-01$ & 3 \\
\hline Luxembourg (BB) & $1 / 29 / 99$ & $9 / 28 / 01$ & & & $1966-01$ & 1 \\
\hline Panama (BB) & $12 / 31 / 92$ & $9 / 28 / 01$ & & & $1966-01$ & 0 \\
\hline Peru (BB) & $12 / 31 / 92$ & $9 / 28 / 01$ & & & $1993-01$ & 3 \\
\hline Philippines (KS) & $12 / 1 / 84$ & $5 / 31 / 99$ & $1969-94$ & 2 & $1966-68,95-01$ & 2 \\
\hline Poland (BB) & $4 / 30 / 91$ & $9 / 28 / 01$ & $1986-97$ & 3 & $1998-01$ & 1 \\
\hline Portugal (KS) & $1 / 1 / 86$ & $4 / 30 / 99$ & $1966-92$ & 3 & $1993-01$ & 0 \\
\hline Russia (B B) & $6 / 30 / 94$ & $9 / 28 / 01$ & $1992-95$ & 1 & $1996-01$ & 7 \\
\hline Saudi Arabia (B B) & $1 / 31 / 94$ & $9 / 28 / 01$ & & & $1966-01$ & 0 \\
\hline Singapore (BB) & $1 / 31 / 85$ & $9 / 28 / 01$ & $1966-77$ & & $1978-01$ & 4 \\
\hline South Africa (BB) & $4 / 29 / 88$ & $9 / 28 / 01$ & $1966-01$ & 2 & & \\
\hline Spain (KS) & $1 / 1 / 75$ & $12 / 31 / 98$ & $1966-93$ & 4 & $1994-01$ & 0 \\
\hline Sweden (KS) & $1 / 1 / 75$ & $5 / 31 / 99$ & $1966-92$ & 2 & $1993-01$ & 0 \\
\hline Switzerland (BB) & $7 / 31 / 89$ & $9 / 28 / 01$ & & & $1992-01$ & 0 \\
\hline Taiwan (BB) & $1 / 31 / 67$ & $9 / 28 / 01$ & $1966-86$ & 3 & $1987-01$ & 9 \\
\hline Thailand (KS) & $12 / 1 / 75$ & $5 / 31 / 99$ & $1966-91$ & 2 & $1992-01$ & 7 \\
\hline Turkey (BB) & $2 / 28 / 92$ & $9 / 28 / 01$ & $1966-89$ & 0 & $1990-01$ & 8 \\
\hline UK (KS) & $1 / 1 / 75$ & $4 / 30 / 99$ & $1966-78$ & 0 & $1979-01$ & 0 \\
\hline US (BB) & $1 / 29 / 60$ & $9 / 28 / 01$ & & & $1966-01$ & 1 \\
\hline Venezuela (KS) & $12 / 1 / 84$ & $5 / 31 / 99$ & $1984-89$ & 3 & $1966-83,90-01$ & 8 \\
\hline Zim babwe (B B) & $9 / 30 / 96$ & $9 / 28 / 01$ & $1980-01$ & 2 & & \\
\hline
\end{tabular}

Figure 8: 
have to imply that for some parameters, a decrease in $q$ is possible. As $\partial q / \partial \phi>0$ always, this is not possible.

Appendix IV: Asymmetric equilibria in the emerging market

Suppose only a portion $l_{E}<1$ of the $L$ agents in the emerging market invest. The stock market equilibrium relation as well as the income relation can easily be rewritten accordingly and it can be checked that world income is the same as in the text. For $0<l_{E}<1$, the profit of investing must be zero, or using the the constant world income equation: $l_{E}+q^{-2}=\frac{\beta\left(w_{E}+w_{I}\right)}{F(2+\beta)}$. The intuition is that an increase in the relative price of assets in the emerging market induces entry which in this case implies a rise in the proportion of agents who invest. It proves convenient to rewrite the fixed cost as $F=\alpha F_{1}$ with $F_{1}=\frac{\beta w_{E}}{2+\beta}$. We then get $l_{E}+q^{-2}=\frac{1}{\alpha s_{w}}$. A modified $Y Y$ curve is derived from the definition of aggregate income in the emerging economy: $L\left(w_{E}+\frac{1}{2} l_{E} p_{E}^{2}\right)$ and the zero profit condition. This defines $s_{Y}$ the share of aggregate income in the emerging market as an increasing function of $q$ :

$$
s_{Y}=\frac{s_{w}(2+\beta)}{2(1+\beta)}+\frac{\beta}{2(1+\beta)}\left(1-\alpha s_{w} q^{-2}\right)
$$

A modified $q q$ curve is derived from the stock market equilibrium:

$$
s_{Y}=\frac{\left(q^{2}-\alpha s_{w}+s_{w} \phi q^{1 / \rho}\right)\left(1-\phi q^{-1 / \rho}\right)}{\left(s_{w}-\alpha s_{w}+q^{2}\right)\left(1-\phi^{2}\right)}
$$

with $l_{E}$ defined by the zero profit condition. It can be shown that such an equilibrium for which 0 $<l_{E}<1$ never exists if $\alpha<1$. This implies that only the equilibrium with all agents investing exists. An example where an asymmetric equilibrium exists is in the autarky situation $(\phi=0)$ if $\alpha>1$. In this case, a symmetric equilibrium with $l_{E}=1$ cannot be an equilibrium as it would involve negative profits. It can be shown easily that $l_{E}=1 / \alpha<1$. In cases with $\phi>0$, asymmetric equilibria can exist if $\alpha$ is sufficiently larger than one. From (A4) and (A5), it can be checked that the modified $Y Y$ and $q q$ curves are similar to those depicted in figure 5 and cross only once. In particular, a decrease in transaction costs has a similar impact whereas all or only a portion of agents invest. The new $q q$ curve shifts to the right as in figure 5 so that both $q$ and $s_{Y}$ rise. The intuition is the same as in the text but now a new variable ajusts: $l_{E}$, the portion of agents who invest. As transaction costs decrease, this portion increases in the emerging market and the price of assets in the industrialized country decrease so $q$ increases. When the level of transaction costs is low enough, all agents in the emerging market invest and we are back to the case analysed in the main text. Hence, the asymmetric equilibria are not qualitatively different from the symmetric ones.

Appendix V: Asymmetric transaction costs

A increase in $\phi_{i n}$ shifts the $q q$ curve to the right as from equation (22), we get:

$$
\partial s_{Y} / \partial \phi_{\text {in }}=\frac{\left[q^{2}+\phi_{\text {out }} q^{1 / \rho}\right]\left(\phi_{\text {out }}-q^{-1 / \rho}\right)}{\left(1-\phi_{\text {in }} \phi_{\text {out }}\right)\left(1+q^{2}\right)}<0
$$

We can sign this expression by the restriction that $s_{Y}<1$. 
Appendix VI: A more general investment cost function

Suppose that the cost function is: $f\left(z_{E}\right)=\frac{1}{m} z_{E}^{m}$ with $m>1$, so that we retain the convexity property of the cost function. In this case, the $Y Y$ schedule becomes:

$$
s_{Y}=\frac{s_{w}(m+\beta)}{m(1+\beta)}+\frac{\beta(m-1)}{m(1+\beta)\left(1+q^{-m /(m-1)}\right)}
$$

and the $q q$ curve:

$$
s_{Y}=\frac{\left(q^{m /(m-1)}+\phi q^{1 / \rho}\right)\left(1-\phi q^{-1 / \rho}\right)}{\left(1+q^{m /(m-1)}\right)\left(1-\phi^{2}\right)}
$$

It remains true that $q<1$ in equilibrium as long as $w_{E}<w_{I}$. The working of figure 4 remains similar. If $m \geq 2 /(2-\rho)$, then the qualitative result of figure 4 is unchanged: a symmetric decrease of transaction costs generates an increase in asset prices and income in the emerging market. A sufficient condition is that $m \geq 2$. However, if $m<2 /(2-\rho)$ and transaction costs are high enough ( $\phi$ is low), then a symmetric decrease in transaction costs can lead to a decrease in asset price and income in the emerging market. At some point however the lower transaction costs lead to increase in asset prices and income. The reason for this result is that the slope of the $q q$ is also altered by a change in $\phi$. The effect of an increase in $\phi$ on the $q q$ curve can be analyzed by looking at how $s_{Y}$ is affected by an increase in $\phi$ for a given $q$ :

$$
\frac{\partial s_{Y}}{\partial \phi}=\frac{\left(1+\phi^{2}\right)\left(q^{1 / \rho}-q^{m /(m-1)-1 / \rho}\right)-2 \phi\left(1-q^{m /(m-1)}\right)}{\left(1+q^{m /(m-1)}\right)\left(1-\phi^{2}\right)^{2}}
$$

This can be positive (implying an upward shift of the $q q$ curve) for $m<2 /(2-\rho)$, large differences in productivities and high transaction costs. This case is shown on figure 9.

Hence, when the cost function is not very convex, financial globalization can in a first phase decrease asset prices and income in the emerging market especially if its productivity level is low. In this case, it also leads in a first phase to a current account surplus in the emerging market. The intuition is that in this case (which can also be interpreted as high risk aversion case) the diversification purpose is strong relative to the arbitrage one: this implies that agents in the industrialized country will not exploit much the difference in price between markets when transaction costs go down (at least for high transaction costs) but agents in the emerging market will want to diversify and buy assets in the industrialized country.

The analysis of the possibility of a crash driven by self-fulfilling expectations is more complex but not fundamentally altered in the case of a more general cost function as long as it is convex. It implies finding parameter values for which the investment is zero if agents expect zero investment and positive if they expect positive investment. 


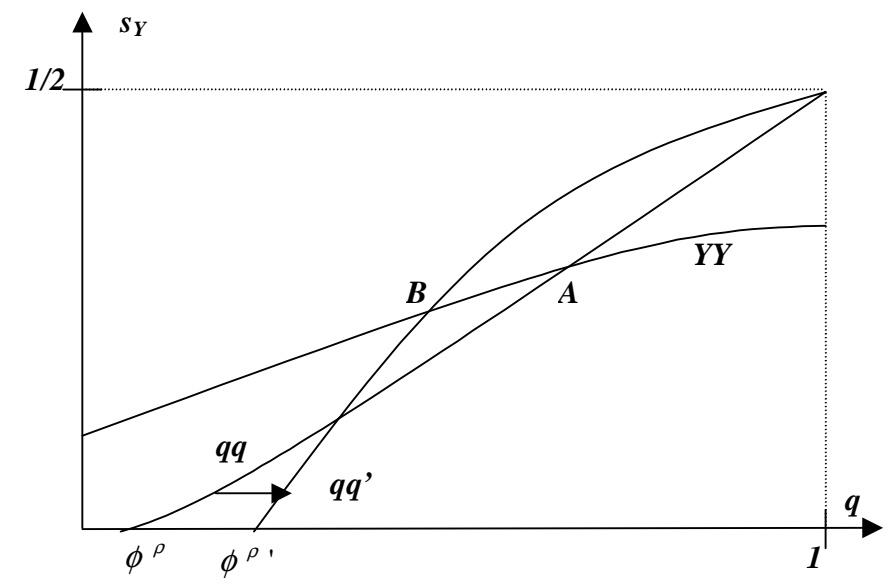

Figure 9: Lower transaction costs: the case of weak convexity and high transaction cost

Appendix VII: The impact of different population size

Because we want to focus on the consequences of lower productivity and wage in emerging market compared to industrialized countries, we have not allowed for different population size between the two countries. Doing this has potentially important consequences because of two features in our model: the market size effect and the fact that a larger population implies a larger number of projects/assets. Hence both demand and supply of assets are affected. To see this suppose now that wages are identical in the two countries but that populations (rather than being equal as in the paper) are $L_{E}$ and $L_{I}$ respectively. The $Y Y$ curve becomes:

$$
s_{Y}=\frac{(2+\beta) L_{E}}{2(1+\beta)\left(L_{E}+L_{I}\right)}+\frac{\beta L_{E}}{2(1+\beta)\left(L_{E}+L_{I} q^{-2}\right)}
$$

where $s_{Y}=L_{E} Y_{E} /\left(L_{E} Y_{E}+L_{I} Y_{I}\right)$ is now the share of the $E$ country in aggregate world income. The $q q$ curve is now:

$$
s_{Y}=\frac{\left(L_{E} q^{2}+L_{I} \phi q^{1 / \rho}\right)\left(1-\phi q^{-1 / \rho}\right)}{\left(L_{E} q^{2}+L_{I}\right)\left(1-\phi^{2}\right)}
$$

The equilibrium is graphed on figure 10 where we assumed that $L_{E}<L_{I}$ :

It can be shown that the equilibrium relative price when $\phi<1$ is less than 1 . Hence, imperfect integration of financial markets implies lower asset prices in the small country. From this point of view the effect resembles a lot the market size effect when wages differ. An increase in population size has however an ambiguous effect. As shown on figure 10 both the $Y Y$ and $q q$ curves are affected. This is because both demand and supply of assets are increased. It can be shown that for low levels of $\phi$ (high transaction costs), the supply effect dominates so that an increase in $L_{E}$ implies a decrease 


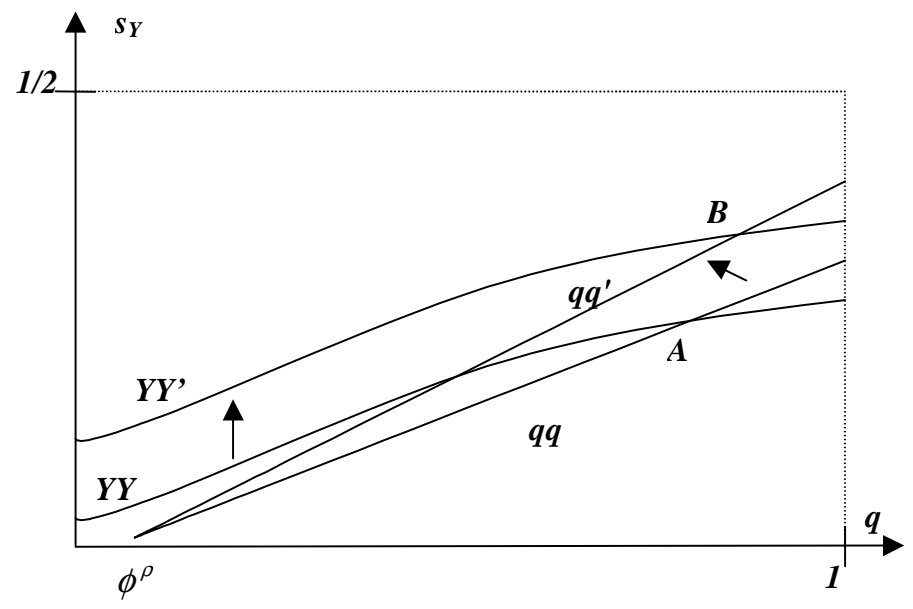

Figure 10: An increase population size of E: the case where asset prices in E decrease

in $q$. For high levels of $\phi$ (low levels of transaction costs), the demand effect dominates so that an increase in $L_{E}$ implies an increase in $q$.

It can be shown that at $\phi=0$ and $\phi=1$, asset prices are identical $(q=1)$ in the two countries (again as long as wage rates are identical) even if population differ. At $\phi=1$, perfect capital mobility, the reason is again perfect arbitrage. At $\phi=0$, financial autarky, this is because the demand and the supply effect of population size cancel each other. A small population implies a lower demand for assets but also implies a small number of assets. Given this, it can be shown that the relative price of assets $q$ is $\mathrm{U}$-shaped as a function of $\phi$ when wages are equal and $L_{E}<L_{I}$.

It can be checked that in the case of pessimistic expectations the expected profit function in the "pessimistic" country is U-shaped as in figure 5. Equation (18) in the text is still valid but with $s_{w}=L_{E} w_{E} /\left(L_{E} w_{E}+L_{I} w_{I}\right)$. It can then be shown that the expected "pessimistic" profit function of the smaller country (in terms of non capital aggregate income) is always below the one of the larger country. The reason the ambiguous effect of large population on asset prices that applies in the optimistic case does not apply when we analyse the vulnerability of crashes is a particular assumption in our model. To simplify the analysis, we assume that the economy in the first period starts with zero zero capital stock or zero projects. Suppose however that agents are endowed with projects. If the aggregate endowment of projects depends positively on population size, a reasonnable assumption, and as projects/assets are substitutes, larger population size would increase the supply of assets and have a negative impact on asset prices in the crash equilibrium. The positive demand effect of larger population would still play a role so that the effect of population size on financial vulnerability would be ambiguous as it is on asset prices in the optimistic equilibrium. 


\section{R eferences}

[1] Acemoglu, D. and F. Zilibotti, 1998," Was Promotheus Unbound by Chance? Risk, Diversification and Growth", J ournal of Political E conomy, 105, 709-751.

[2] Aghion, P., Bachetta, P. and A. Banerjee, 2000: 'Capital Markets and the Instability of Open Economies' CEPR DP 2083.

[3] Arteta, C., B. Eichengreen and C. Wyplosz, 2001, "When Does Capital Account Liberalization Help More than it Hurts?" CEPR DP 2910.

[4] Bekaert, G. and C. Harvey,1995, "Time-Varying World Market Integration", J ournal of F inance, $50(2)$.

[5] Bekaert, G. and C. Harvey, 2000, 'Foreign Speculators and Emerging Equity Markets', J ournal of Finance, 55(2), pp. 565-613.

[6] Bekaert, G, C. Harvey and R. Lundblad, 2001, "Does Financial Liberalization Spur Growth?", NBER working paper 6724, 1-63.

[7] Burnside, C. M. Eichenbaum and S. Rebelo, 1998, "Prospective Deficits and the Asian Currency Crisis", NBER Working Paper 6758.

[8] Caballero, R. and A. Krishnarmurthy, 1998, "Emerging Market Crises: An Asset Markets Perspective,", NBER WP 6843.

[9] — 2000, "International and Domestic Collateral Constraints in a Model of Emerging Market Crises," NBER WP 7971.

[10] Calvo G. and E. Mendoza, 2000, "Capital-Markets Crises and Economic Collpases in Emerging Markets: An Informational-Frictions Approach", American Economic Review: Papers and P roceedings, May.

[11] Chang, R. and A. Velasco, 1998, "Financial Crises in Emerging Markets: a Canonical Model", NBER Working Paper 6606.

[12] Chari, A. and P. Henry, 2002, "Capital Account Liberalization: Allocative Efficiency or Animal Spirits?", NBER working paper 8908.

[13] Claessens, S. D. Klingebiel and S. Schmukler, 2001, "The Future of Stock Markets in Emerging Economies: Evolution and Prospects", paper presented at the Fifth Annual Brookings-Wharton Conference on Financial Srvices, Washington DC, 2002. 
[14] Corsetti, G., P. Pesenti and N. Roubini, 1999, "Fundamental Determinants of the Asian Crisis: The Role of Financial Fragility and External Imbalances", forthcoming in T. Ito and A. Krueger (eds.), Regional and Global Capital Flows: Macroeconomic Causes and Consequences, Chicago, IL: University of Chicago Press.

[15] Demigüc-Kunt A. and E. Detragiache (1998), "Financial Liberalization and Financial Fragility", IMF Working Paper.

[16] De Jong F. and F.A. de Roon, 2001, "Time-varying Market Integration and Expected Returns in Emerging Markets", CEPR DP 3102.

[17] Diaz-Alejandro, C., 1985, "Goodbye Financial Repression, Hello Financial Repression", J ournal of Development Economics, 19, 1-24.

[18] Edison H. and F. Warnock, 2001, "A Simple Measure of the Intensity of Capital Controls", International Finance Discussion Papers, number 708.

[19] Edwards, S., 2000, "Capital Mobility and Economic Performance: Are Emerging Economies Different?" UCLA working paper.

[20] Eichengreen, B., A. Rose and C. Wyplosz,1995, "Exchange Rate Mayhem: The Antecedents and Aftermaths of Speculative Attacks", Economic Policy, 21 pp 249-296.

[21] Eizenman, J., 2002, "Financial Opening: Evidence and Policy Options", NBER WP 8900.

[22] Gordon, R. and L. Bovenberg, 1996, "Why Is Capital so Immobile Internationally? Possible Explanations and Implications for Capital Income Taxation", American Economic Review, 86, 5, 1057-75.

[23] Henry, P. B., 2000, 'Do stock market liberalizations cause investment booms?', J ournal of Financial Economics, 58(1-2), pp. 301-334.

[24] IMF, various years, "Annual Report on Exchange Arrangements and Exchange Restrictions".

[25] Kaminsky G. and C. Reinhart, 1999, "The Twin Crises: The Causes of Banking and Balance-ofPayments Problems", American Economic Review, 89 (3), p 473-500.

[26] Kaminsky G. and S. Schmukler, (2001), "On Booms and Crashes: Financial Liberalization and Stock Market Cycles", Mimeo.

[27] Krugman, P. (1999), "Balance Sheets, the Transfer Problem, and Financial Crises," in Isard, Razin and Rose, eds., International Finance and Financial Crises: Essays in Honor of Robert Flood, 31-56, B oston, K luwer A cademic Publishers. 
[28] Krugman, P. and A. Venables, "Globalization and the Inequality of Nations", The Quarterly J ournal of E conomics, Vol. 110, No. 4. (Nov., 1995), pp. 857-880.

[29] Mckenzie, D. (2001), "The impact of capital controls on growth convergence", J ournal of Economic Development, 26(1), June.

[30] Martin P. and H. Rey (2001), "Financial Supermarkets: Size Matters for Asset Trade", NBER WP 8476

[31] Matsuyama (2000), 'Financial Market Globalization and Endogenous Inequality of Nations', DP 1300, The Center For Mathematical Studies in Economics and Management Science, Northwestern University.

[32] McKinnon, R. and Huw Pill,1999, "Exchange-Rate Regimes for Emerging Markets: Moral Hazard and International Overborrowing", Oxford Review of Economic Policy 15(3)

[33] Mendoza, E. (2001), "Credit, Prices and Crashes: Business Cycles with a Sudden Stop", NBER working paper 8338 .

[34] Mendoza, E. and K. Smith (2001), "Margin Calls, Trading Costs and Asset Prices in Emerging Markets: The Financial Mechanics of the 'Sudden Stops' Phenomenon", Mimeo, Duke University.

[35] Meng Q. and A. Velasco (1999), "Can Capital Mobility be Destabilizing?", NBER Working Paper 7263.

[36] Murphy, K. A. Schleifer and R. Vishny (1989), "Indsutrialization and the Big Push", J ournal of Political Economy, volume volume 97, page 1003-1026.

[37] Obstfeld, M. and K. Rogoff, 2001, "The Six Major Puzzles of International Macroeconomics Solved", forthcoming NBER Macro Annual.

[38] Pagano, M., 1993, "The Floatation of Companies on the Stock Market: a Coordination Failure Model", European E conomic Review, 37, 1101-25.

[39] Rossi, M. (1999), "Financial Fragility and Economic Performance in Developing Countries: Do Capital Controls, Prudential Regulation and Supervision Matter?", IMF Working Paper 99/66.

[40] Schneider, M. and A. Tornell, (2000), "Balance Sheet Effects, Bailout Guarantees and Financial Crises," NBER Working Paper No.8060.

[41] Shleifer, A., 1986, "Do Demand Curves for Stocks Slope Down?", Journal of Finance 41, 579-590.

[42] Stulz, R., (1999), 'Globalization of Equity Markets and the Costs of Capital', NBER working paper no. 7021. 
[43] Tornell, A. and F. Westermann, 2001, "Boom-Bust Cycles: Facts and Explanation", mimeo.

[44] Weil, P. (1990), "Nonexpected Utility in Macroeconomics", Quartely J ournal of E conomics, volume 105, issue 1, 29-42.

[45] Wyplosz C. (2001), "How Risky is Financial Liberalization in the Developing Countries?", CEPR DP 2724. 